\title{
Nopol-Based Quinoline Derivatives as Antiplasmodial Agents
}

\author{
Rogers J. Nyamwihura, Huaisheng Zhang, Jasmine T. Collins, Olamide Crown and Ifedayo Victor Ogungbe *
}

\author{
Department of Chemistry, Physics, and Atmospheric Sciences, Jackson State University, Jackson, MS 39217, USA; \\ rogersnyamwihura@yahoo.com (R.J.N.); huaishengzhang@medicilon.com.cn (H.Z.); \\ jasmine.collins@wvstateu.edu (J.T.C.); olamide.crown@jsums.edu (O.C.) \\ * Correspondence: ifedayo.v.ogungbe@jsums.edu; Tel.: +1-601-979-3719
}

Citation: Nyamwihura, R.J.; Zhang, H.; Collins, J.T.; Crown, O.; Ogungbe, I.V. Nopol-Based Quinoline Derivatives as Antiplasmodial Agents. Molecules 2021, 26, 1008. https://doi.org/10.3390/ molecules 26041008

Academic Editors: Thomas J. Schmidt, Valeria Patricia Sülsen and Josphat Matasyoh

Received: 17 January 2021

Accepted: 11 February 2021

Published: 14 February 2021

Publisher's Note: MDPI stays neutral with regard to jurisdictional claims in published maps and institutional affiliations.

Copyright: (c) 2021 by the authors. Licensee MDPI, Basel, Switzerland. This article is an open access article distributed under the terms and conditions of the Creative Commons Attribution (CC BY) license (https:// creativecommons.org/licenses/by/ $4.0 /)$.

\begin{abstract}
Malaria remains a significant cause of morbidity and mortality in Sub-Saharan Africa and South Asia. While clinical antimalarials are efficacious when administered according to local guidelines, resistance to every class of antimalarials is a persistent problem. There is a constant need for new antimalarial therapeutics that complement parasite control strategies to combat malaria, especially in the tropics. In this work, nopol-based quinoline derivatives were investigated for their inhibitory activity against Plasmodium falciparum, one of the parasites that cause malaria. The nopylquinolin-8-yl amides (2-4) were moderately active against the asexual blood stage of chloroquinesensitive strain $P f 3 D 7$ but inactive against chloroquine-resistant strains $P f \mathrm{~K} 1$ and $P f$ NF54. The nopyl-quinolin-4-yl amides and nopyl-quinolin-4-yl-acetates analogs were generally less active on all three strains. Interesting, the presence of a chloro substituent at $C 7$ of the quinoline ring of amide 8 resulted in sub-micromolar $\mathrm{EC}_{50}$ in the $\mathrm{PfK} 1$ strain. However, 8 was more than two orders of magnitude less active against $P f 3 D 7$ and $P f$ NF54. Overall, the nopyl-quinolin-8-yl amides appear to share similar antimalarial profile (asexual blood-stage) with previously reported 8-aminoquinolines like primaquine. Future work will focus on investigating the moderately active and selective nopylquinolin-8-yl amides on the gametocyte or liver stages of Plasmodium falciparum and Plasmodium vivax.
\end{abstract}

Keywords: Plasmodium falciparum; aminoquinoline; nopol; $\alpha$-pinene; malaria

\section{Introduction}

Malaria is endemic in 91 countries, which accounts for $40 \%$ of the world's population. According to the US Centers for Disease Control and Prevention, an estimated 228 million malaria cases occurred worldwide in 2018 , and 405,000 people died [1]. It remains a serious public health problem in many developing tropical countries. There is no approved vaccine to prevent malaria for the general population. However, there are several therapies whose effectiveness is limited by the strain of Plasmodium responsible for the disease or by drug resistance. Artemisinin-based combination therapies (ACTs) are the first-line drugs for the treatment of malaria caused by P. falciparum in most malaria-endemic countries, while chloroquine (CQ) or ACT is used for the treatment of uncomplicated P. vivax in countries endemic for vivax malaria. Combinations of primaquine with CQ or ACTs are used for radical cure of relapsing malaria parasites due to $P$. vivax and P. ovale [2]. The 8 -aminoquinoline-based drug primaquine (PQ) is also used as a gametocytocidal agent to reduce the transmission of P. falciparum in areas with verified artemisinin resistance [3]. 4-aminoquinoline-based compounds like chloroquine are known for their ability to accumulate as dicationic molecules in the plasmodial food vacuole and inhibit heme detoxification [4-6]. Since malarial parasites lack the oxygenase required to metabolize heme, soluble heme (iron-protoporphyrin IX) is converted into an insoluble and inert form called hemozoin, which the parasite can efficiently excrete. When these quinoline-based antimalarial drugs interfere with the conversion of soluble heme to hemozoin, heme accumulates and becomes toxic to the parasite because of radical reactions, damaged cell membranes, and cellular proteopathy $[7,8]$. The development of resistance to 4-aminoquinoline-based 
compounds such as CQ is linked to mutations in CQ resistance transporter (PfCRT) in $P$. falciparum and upregulation in the expression of CQ resistance transporter (PvCRT) in P. vivax. Mutations in P. falciparum multidrug-resistant protein 1 have also been linked to resistance to artemisinin, halofantrine, mefloquine, and quinine. The mutations and/or upregulated expression shield the parasites from drug accumulation and are viewed as consequences of evolutionary pressure to increase the rate of removal of drugs from the compartment containing the putative drug target(s) [9-12]. The mechanism of action of 8-aminoquinoline-based antimalarials is unclear. However, some studies have suggested that it involves the generation of reactive oxygen species as well as inhibition of the electron transport chain because of metabolic transformation $[13,14]$. Quinoline-based compounds remain a robust class of molecules for new antimalarial agents. In this study, quinoline compounds that possess an $\alpha$-pinene scaffold were synthesized (Scheme 1) and evaluated for their antiplasmodial activities. $\alpha$-pinene is a common constituent of essential oils, and it was previously shown to have antiplasmodial activity [15]. Also, phloroglucinol-terpenes robustadial A and B from Eucalyptus robusta, containing an $\alpha$-pinene moiety, have been reported to have antiplasmodial activities [16].

\section{Results and Discussion}

The synthetic route to the compounds is shown in Scheme 1 below. To obtain amides 1-6 and esters 7-12, (1R)-(-)-nopol (N1) was oxidized to its corresponding acid using Jones reagent, and the acid was coupled with the corresponding aminoquinolines and quinolinols. Oxidation of nopol produced a relatively low yield of nopoic acid (N2). This is likely due to cationic rearrangement of the pinene ring to relieve angle strain caused by the four-membered ring bridgehead [17]. The initial reaction of nopoic acid with 5-methoxy-8aminoquinoline and 8-aminoquinoline, using HBTU-HOBT as coupling reagents, produced two stereoisomers each (1-4). The diastereotopic $\alpha$-protons in $\mathbf{1}(\delta 3.32$ and $3.13 \mathrm{ppm})$ and 3 ( $\delta 3.34$ and $3.16 \mathrm{ppm}$ ) share similar magnetic fields compared to the diastereotopic $\alpha-$ protons in 2 ( $\delta 3.56-3.48$ and $2.88 \mathrm{ppm})$ and 4 ( $\delta 3.55-3.48$ and $2.92-2.82 \mathrm{ppm})$. The observed anisotropic effect is likely due to two different orientations of the quinoline ring in the two sets of isomers. The amides (1-4) were subsequently tested for their antiplasmodial activities in vitro using the P. falciparum 3D7 ( $P f 3 D 7$, chloroquine-sensitive strain), and all four compounds showed moderate but selective low micromolar potency against the parasite (Table 1). The bioactivity $\left(\mathrm{EC}_{50}\right)$ of the compounds was similar to reported $\mathrm{EC}_{50}$ values for 8-aminoquinolines like primaquine [18]. This was particularly interesting because the compounds lack the essential side-chain amino moiety typical of quinoline-based antimalarials [19]. Therefore, to extend the compound's series and to investigate the potentially more potent 4-aminoquinoline derivatives, a set of 4-aminoquinoline-based analogs (5-12) were synthesized and evaluated against Pf3D7. Amides 5 and $\mathbf{6}$ were weakly active (EC 5026.4 and $17.1 \mu \mathrm{M}$, respectively) against Pf3D7, and 5 was significantly more cytotoxic to HepG2 (hepatocarcinoma) cells compared to the corresponding 8-aminoquinolyl analogs (3 and 4, Table 1). Esters 7-12 were generally inactive against Pf3D7 apart from $9\left(\mathrm{EC}_{50} 6.2 \mu \mathrm{M}\right)$. Three other esters, 13-15, were synthesized using 7-chloro-2-methyl4-quinolinecarboxylic acid, 2-chloro-4-quinolinecarboxylic acid, and 2-indolecarboxylic acid, respectively. Compound 13 displayed very weak antiplasmodial activity while 14 and 15 were moderately active against Pf3D7. The 4-aminoquinoline nopyl amides and esters displayed much weaker activities against $P f 3 D 7$ than the 8-aminoquinoline-derived compounds. To determine if the compounds are active against strains of $P$. falciparum that are less sensitive to chloroquine, compounds 3-8 and 14 were assayed against the NF54 and K1 strains of P. falciparum. Compounds 3, 4, and 14 were inactive against both strains, while 5 and 6 were weakly active against both strains (Table 2). Surprisingly, compound 8, which bears the 7-chloroquinolyl moiety, was significantly more active against the "multidrug-resistant" K1 strain than the NF54 and 3D7 strains $\left(\mathrm{EC}_{50}\right.$ PfK1 $0.16 \mu \mathrm{M}$ vs. $\mathrm{EC}_{50 N F 54} 23.3 \mu \mathrm{M}$ and $\mathrm{EC}_{50 \text { Pf3D7 }}>50 \mu \mathrm{M}$ ). It is unclear why the $\mathrm{K} 1$ was more susceptible to 8 . However, a previous report has shown that mutations in $\mathrm{CQ}$ resistance transporter, 
like in the K1 strain, can enhance antimalarial agents' antiplasmodial activities against CQ-resistant strains [20]. For example, the antiviral agent amantadine can accumulate in the cytosol, act on its molecular target, and exert more significant antiplasmodial activity because the $76 \mathrm{I}-\mathrm{PfCRT}{ }^{\mathrm{K} 1}$ transporter variant can transport it back into the cytosol from the food vacuole more effectively than the wild-type transporter ( $\left.\mathrm{PfCRT}^{\mathrm{K} 1}\right)$. It is likely that 8 is transported with greater efficiency by $P f C R T$ in the K1 strain and able to engage effectively with a putative cytosolic target, or its transportation out of the food vacuole is significantly hindered in the K1 strain and therefore displayed a more substantial anti-hemozoin effect in the parasite.

Table 1. Antiplasmodial activity of compounds 1-16.

\begin{tabular}{|c|c|c|c|c|c|}
\hline Compound & $\mathbf{R}$ & $\begin{array}{c}P f 3 D 7 \\
\mathrm{EC}_{50}(\mu \mathrm{M}) \\
\left(^{(\mathrm{SI}))^{\mathrm{a}}}\right.\end{array}$ & $\begin{array}{c}P f \text { NF54 } \\
\text { EC }_{50}(\mu \mathrm{M}) \\
\left(^{(S I)}\right)^{a}\end{array}$ & $\begin{array}{c}P f \mathrm{~K} 1 \\
\mathrm{EC}_{50}(\mu \mathrm{M}) \\
(\mathrm{SI})^{\mathrm{a}}\end{array}$ & $\begin{array}{c}\text { Hep G2 } \\
\mathrm{CC}_{50}(\mu \mathrm{M})\end{array}$ \\
\hline 1 & & $\begin{array}{l}5.25 \pm 0.70 \\
\quad(13.4)\end{array}$ & nd & nd & $70.8 \pm 1.26$ \\
\hline 2 & & $\begin{array}{l}2.72 \pm 0.28 \\
\quad(>58.8)\end{array}$ & nd & nd & $>160$ \\
\hline 3 & & $\begin{array}{l}2.19 \pm 0.15 \\
\quad(>73.1)\end{array}$ & $>50$ & $>50$ & $>160$ \\
\hline 4 & & $\begin{array}{c}2.57 \pm 0.02 \\
\quad(>62.3)\end{array}$ & $>50$ & $>50$ & $>160$ \\
\hline 5 & & $\begin{array}{c}26.4 \pm 1.70 \\
(0.2)\end{array}$ & $\begin{array}{c}23.4 \pm 0.14 \\
\quad(0.2)\end{array}$ & $\begin{array}{c}13.9 \pm 2.1 \\
(0.3)\end{array}$ & $3.98 \pm 0.7$ \\
\hline 6 & & $\begin{array}{c}17.1 \pm 1.80 \\
(0.8)\end{array}$ & $\begin{array}{c}21.37 \pm \\
1.70(0.7)\end{array}$ & $\begin{array}{c}7.84 \pm \\
0.57(1.8)\end{array}$ & $14.26 \pm 1.2$ \\
\hline 7 & & $>50$ & $>50$ & $>28$ & $>160$ \\
\hline 8 & & $>50$ & $\begin{array}{c}23.27 \pm \\
3.78(>6.8)\end{array}$ & $\begin{array}{c}0.164 \pm \\
0.06(>976)\end{array}$ & $>160$ \\
\hline 9 & & $\begin{array}{l}6.15 \pm 0.98 \\
\quad(>26)\end{array}$ & nd & nd & $>160$ \\
\hline 10 & & $\begin{array}{c}21.39 \pm 5.06 \\
\quad(2.3)\end{array}$ & nd & nd & $48.50 \pm 1.12$ \\
\hline
\end{tabular}




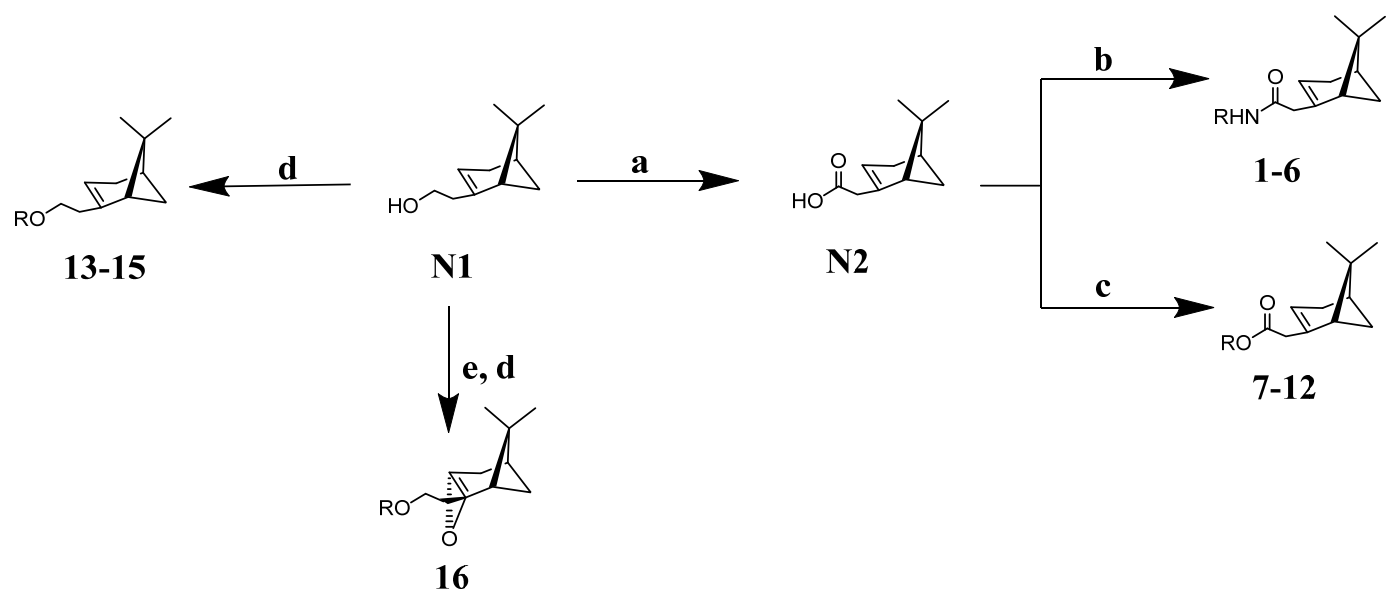

Scheme 1. Synthesis of compounds 1-16. Reagent and conditions: (a) Jones reagent: Acetone, $\mathrm{H}_{2} \mathrm{O}, 50{ }^{\circ} \mathrm{C}, 12 \mathrm{~h}, 33-45 \%$ (b) DMF, HBTU, HOBT, DIEA, RNH 2 , r.t, 16 h, 20-40\% (c) THF, EDCI, DMAP, ROH, DIEA, $0{ }^{\circ} \mathrm{C}-$ r.t, 3 h, 25-45\% (d) THF, EDCI, DMAP, RCOOH, DIEA, $0{ }^{\circ} \mathrm{C}-$ r.t, 3 h, 45-55\% (e) 2:1 ethyl acetate/acetone, $\mathrm{NaHCO}_{3}$, r.t, 5 min, then, Oxone ${ }^{\circledR}$ salt $\left(\mathrm{KHSO}_{5}\right.$, $\mathrm{K}_{2} \mathrm{SO}_{4}$ ) in $\mathrm{H}_{2} \mathrm{O}, 1 \mathrm{~h}, 40 \%$.

Table 2. Antiplasmodial activity of compounds 1-16.

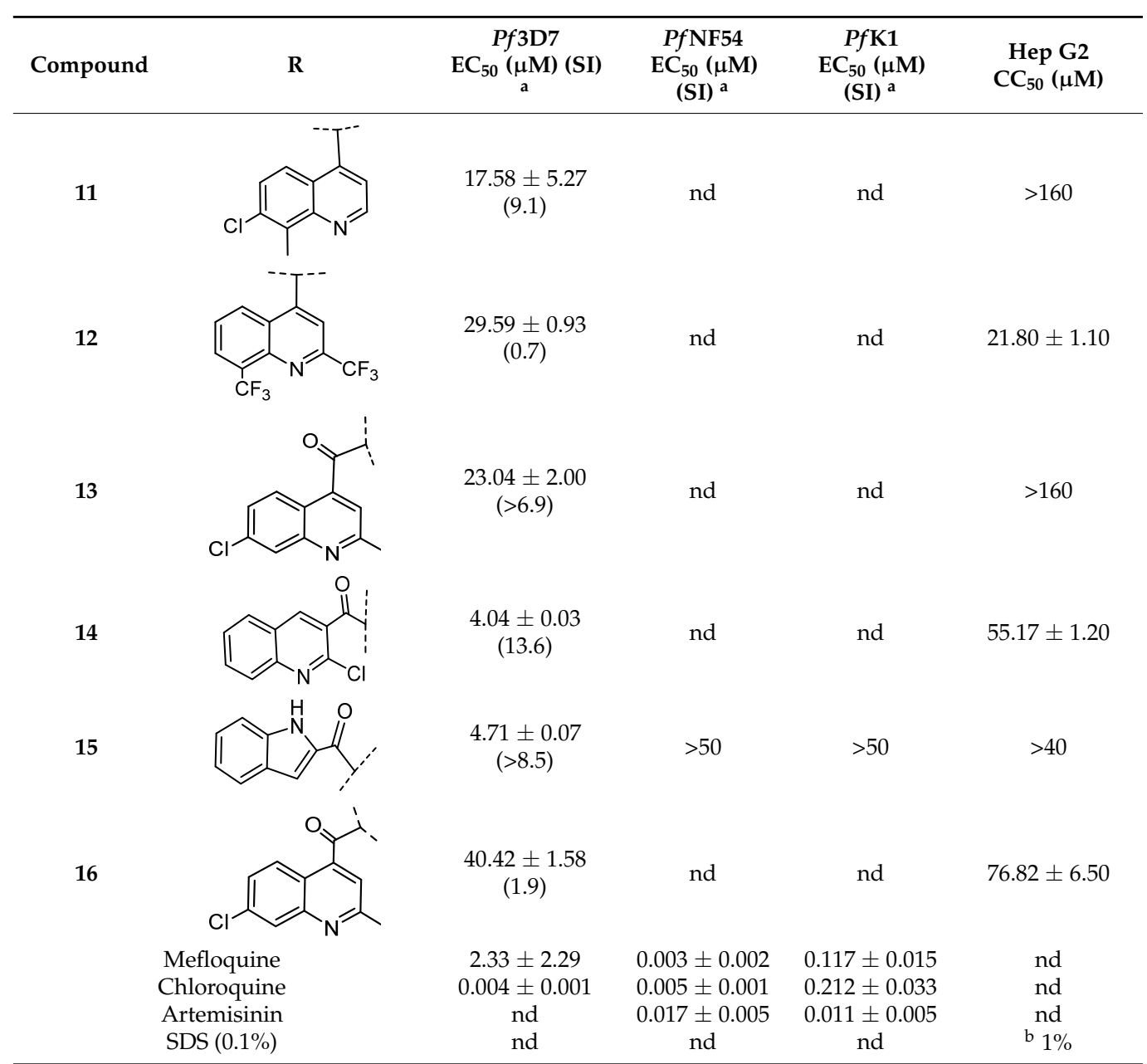

a Selectivity index $\left(\mathrm{CC}_{50} / \mathrm{EC}_{50}\right) ;{ }^{\mathrm{b}}$ Percent viability; nd = not determined.

Synthetic efforts to introduce epoxy and vicinal diol groups to increase aqueous solubility via the unsaturation in the nopol substructure for 1-15 were unsuccessful [21-23]. However, $\mathbf{1 6}$ was synthesized via epoxidation of nopol followed by esterification reaction 
with 7-chloro-2-methyl-4-quinolinecarboxylic acid using EDCI and DMAP. Compound 16 was weakly active but nonselective against $P f 3 D 7$.

In conclusion, the 8-aminoquinolyl amides of nopol were found to be moderately active against the chloroquine-sensitive strain of P. falciparum (Pf3D7), while the corresponding 4-aminoquinolyl analogs were generally more active on the multidrug-resistant K1 strain, especially ester $\mathbf{8}$. Future efforts will be directed towards (1) evaluating the antiplasmodial activity of the 8-aminoquinolyl amides on different life stages of $P$. falciparum, as well as on P. vivax and P. ovale, and (2) adding an amino functionality to the $\alpha$-pinene or another similar scaffold to potentially enhance the antiplasmodial activities and to understand further the structure-activity relationships of compounds 1-4, 8, 9, and 14 .

\section{Materials and Methods}

\subsection{Compound Characterization}

All reagents were purchased from commercial sources and used without further purification. The ${ }^{1} \mathrm{H}$ and ${ }^{13} \mathrm{C}-\mathrm{NMR}$ data were obtained Varian $500 \mathrm{MHz}$ (Agilent, Santa Clara, CA, USA) and Bruker Ultrashield Avance 400 (Bruker, Billerica, MA, USA) spectrometers. Thin layer chromatography (TLC) and NMR were used to monitor reactions and determine compound purity. Compounds were purified by silica gel (Sortech, Norcross, GA, USA, $60 \AA, 200-500 \mu \mathrm{m}(35 \times 70$ mesh)) column chromatography or on pre-coated preparative TLC plates (SiliCycle Inc, Quebec City, Canada, $1000 \mu \mathrm{m}, 20 \times 20 \mathrm{~cm}$ ). High-resolution mass spectrometric (HRMS) data was obtained on a Synapt G2 HDMS instrument operated in positive or negative ESI mode. Spectra are provided as supplementary information (Supplementary Figure S1.1a-S1.16b).

\subsection{Synthesis of (R)-(-)-Nopoic Acid Using Jones Reagent}

$(R)-(-)-N o p o l(2.2 \mathrm{~g}$, Sigma-Aldrich, St. Louis, MO, USA, 98\% purity) was placed in a round bottom flask containing a magnetic stirring bar, and $20 \mathrm{~mL}$ of acetone was added. The solution was stirred in an ice-water bath for $10 \mathrm{~min}$. To the solution, $10 \mathrm{~mL}$ of 3.88 M Jones reagent (Made from Fisher Scientific's Chromium(VI) oxide, 99+\% purity)in acetone was slowly added for $1 \mathrm{~h}$. TLC was used to monitor the reaction progress. Once no more nopol was detected on analytical TLC, $1-2 \mathrm{~mL}$ of isopropanol was added to consume excess Jones reagent. The reaction turned brownish with the subsequent formation of dark green precipitate at the bottom of the flask. The reaction was washed with $20 \mathrm{~mL}$ of saturated $\mathrm{NaHCO}_{3}$ solution, and the crude product was extracted with $45 \mathrm{~mL}$ of ethyl acetate (EtOAc). The EtOAc extract was washed with brine and dried over $\mathrm{MgSO}_{4}$ and concentrated under vacuum. Pure nopoic acid was obtained by column chromatography using 85:1 $\mathrm{CHCl}_{3} /$ ethyl acetate $\left(\mathrm{R}_{\mathrm{f}}=0.32\right)$. Pure nopoic acid was obtained in $30 \%$ yield. ${ }^{1} \mathrm{H}-\mathrm{NMR}\left(500 \mathrm{MHz}, \mathrm{CDCl}_{3}\right) \delta 11.48(\mathrm{~s}, 1 \mathrm{H}, \mathrm{COOH}), 5.42\left(\mathrm{~s}, 1 \mathrm{H}, \mathrm{H}-3^{\prime}\right), 3.01(\mathrm{dd}, J=15.7$, $\left.15.2 \mathrm{~Hz}, 2 \mathrm{H}, \mathrm{H}-10^{\prime}\right), 2.38\left(\mathrm{~m}, 1 \mathrm{H}, \mathrm{H}-6^{\prime}\right), 2.33-2.19\left(\mathrm{~m}, 2 \mathrm{H}, \mathrm{H}-4^{\prime}\right), 2.14(\mathrm{td}, J=5.6,1.6 \mathrm{~Hz}$, $\left.1 \mathrm{H}, \mathrm{H}-5^{\prime}\right), 2.09\left(\mathrm{~m}, 1 \mathrm{H}, \mathrm{H}-\mathrm{1}^{\prime}\right), 1.28\left(\mathrm{~s}, 3 \mathrm{H}, \mathrm{H}-9^{\prime}\right), 1.22\left(\mathrm{~d}, J=8.7 \mathrm{~Hz}, 1 \mathrm{H}, \mathrm{H}-6^{\prime}\right), 0.83(\mathrm{~s}, 3 \mathrm{H}$, H-8 $\left.{ }^{\prime}\right) .{ }^{13} \mathrm{C}-\mathrm{NMR}\left(126 \mathrm{MHz}, \mathrm{CDCl}_{3}\right) \delta 178.0(\mathrm{C}=\mathrm{O}), 140.5\left(\mathrm{C}-2^{\prime}\right), 121.3\left(\mathrm{C}-3^{\prime}\right), 45.9\left(\mathrm{C}-10^{\prime}\right), 42.4$ $\left(\mathrm{C}-5^{\prime}\right), 40.5\left(\mathrm{C}-1^{\prime}\right), 38.1\left(\mathrm{C}-7^{\prime}\right), 31.7\left(\mathrm{C}-6^{\prime}\right), 31.5\left(\mathrm{C}-4^{\prime}\right), 26.2\left(\mathrm{C}-9^{\prime}\right), 20.9\left(\mathrm{C}-8^{\prime}\right)$.

\subsection{Synthesis of (2-(6,6-dimethylbicyclo[3.1.1]hept-2-en-2-yl)-N-(5-methoxyquinolin-8-yl Acetamide (1 and $\mathbf{2}$ )}

To a round bottom flask containing $3 \mathrm{~mL}$ of $\mathrm{N}, \mathrm{N}$-dimethylformamide (DMF, Fisher Scientific, $>99.8 \%$ ), nopoic acid ( $200 \mathrm{mg}, 1.1 \mathrm{mmol}, 1.0 \mathrm{eq}$.) was added, followed by $0.1 \mathrm{~mL}$ of $\mathrm{N}, \mathrm{N}$-diisopropylethylamine (DIEA, Sigma-Aldrich, $99.5 \%$ purity), $N, N, N^{\prime}, N^{\prime}$-Tetramethyl$\mathrm{O}$-(1H-benzotriazol-1-yl)uronium hexafluorophosphate (HBTU, Sigma-Aldrich, 98\% purity, $400.3 \mathrm{mg}, 0.1 \mathrm{mmol}$ ), and HOBT (1-Hydroxybenzotriazole hydrate, $98 \%$ purity, $144.74 \mathrm{mg}$, $1.1 \mathrm{mmol}, 1.0 \mathrm{eq}$.) [24]. The reaction mixture was stirred at room temperature for $30 \mathrm{~min}$, and 5-methoxy-8-aminoquinoline (186.3 mg, $1.1 \mathrm{mmol}$, and $1.0 \mathrm{eq}$, Sigma-Aldrich, 95\% purity) was added to it. The reaction was allowed to run for $16 \mathrm{~h}$. TLC results show some unreacted amine and activated nopoic acid with two prominent product spots. The 
compounds (1 and 2) were purified using preparative TLC (10:1 hexane/ethyl acetate, $R_{\mathrm{f}}=0.55(\mathbf{1})$ and $\left.0.68(2)\right)$, and the overall product yield was $35 \%$.

\subsubsection{Compound 1}

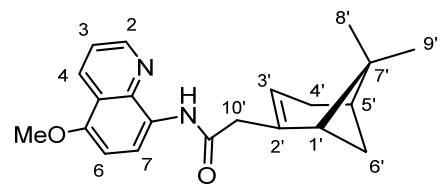

${ }^{1} \mathrm{H}-\mathrm{NMR}\left(500 \mathrm{MHz}, \mathrm{CDCl}_{3}\right) \delta 9.81(\mathrm{~s}, 1 \mathrm{H}, \mathrm{NH}), 8.79$ (dd, J = 4.2, $\left.1.7 \mathrm{~Hz}, 1 \mathrm{H}, \mathrm{H}-2\right)$, $8.68(\mathrm{~d}, J=8.6 \mathrm{~Hz}, 1 \mathrm{H}, \mathrm{H}-6), 8.56(\mathrm{dd}, J=8.4 \mathrm{~Hz}, J=1.7 \mathrm{~Hz}, 1 \mathrm{H}, \mathrm{H}-4), 7.42(\mathrm{dd}, J=8.4 \mathrm{~Hz}$, $J=4.2 \mathrm{~Hz}, 1 \mathrm{H}, \mathrm{H}-3), 6.83(\mathrm{~d}, J=8.6 \mathrm{~Hz}, 1 \mathrm{H}, \mathrm{H}-7), 5.66\left(\mathrm{~m}, 1 \mathrm{H}, \mathrm{H}-3^{\prime}\right), 3.98$ (s, 3H, OMe), 3.32 $\left(\mathrm{d}, J=14.2 \mathrm{~Hz}, 1 \mathrm{H}, \mathrm{H}-10^{\prime}\right), 3.13\left(\mathrm{~m}, 1 \mathrm{H}, \mathrm{H}-10^{\prime}\right), 2.43-2.39\left(\mathrm{~m}, 2 \mathrm{H}, \mathrm{H}-6^{\prime}, \mathrm{H}-4^{\prime}\right), 2.35-2.29$ (m, $\left.1 \mathrm{H}, \mathrm{H}-1^{\prime}\right), 2.22\left(\mathrm{~m}, 1 \mathrm{H}, \mathrm{H}-5^{\prime}\right), 2.13\left(\mathrm{~m}, 1 \mathrm{H}, \mathrm{H}-4^{\prime}\right), 1.48\left(\mathrm{~d}, J=8.7 \mathrm{~Hz}, 1 \mathrm{H}, \mathrm{H}-6^{\prime}\right), 1.26(\mathrm{~s}, 3 \mathrm{H}$, H-9'), 0.85 (s, 3H, H-8 $) .{ }^{13} \mathrm{C}-\mathrm{NMR}\left(126 \mathrm{MHz}, \mathrm{CDCl}_{3}\right) \delta 169.1$ (C=O), 150.1 (C-5), 148.6 (C-2), 142.2 (C-2'), 139.2 (C-8), 131.1 (C-6), 128.1 (C-8a), 122.3 (C7), 120.6 (C-3), 120.4 (C-4a), 116.4 $\left(\mathrm{C}-3^{\prime}\right), 104.3(\mathrm{C}-4), 55.8(\mathrm{OMe}), 46.9\left(1^{\prime}\right), 45.9\left(\mathrm{C}-10^{\prime}\right), 40.4\left(\mathrm{C}-5^{\prime}\right), 38.1\left(\mathrm{C}-6^{\prime}\right), 31.9\left(\mathrm{C}-7^{\prime}\right), 31.6$ $\left(\mathrm{C}-4^{\prime}\right), 26.1\left(\mathrm{C}-9^{\prime}\right), 20.9\left(\mathrm{C}-8^{\prime}\right)$. HRMS: $[\mathrm{M}+\mathrm{H}]^{+}: 337.1916 \mathrm{~m} / \mathrm{z}$ calculated for $\mathrm{C}_{21} \mathrm{H}_{25} \mathrm{~N}_{2} \mathrm{O}_{2}$, found $337.1910 \mathrm{~m} / \mathrm{z}$.

\subsubsection{Compound 2}<smiles>COc1ccc(NC(=O)CC2=CCC3CC2C3(C)C)c2ncccc12</smiles>

${ }^{1} \mathrm{H}-\mathrm{NMR}\left(500 \mathrm{MHz}, \mathrm{CDCl}_{3}\right) \delta 9.49$ (s, 1H, NH), 8.79 (dd, $\left.J=4.3,1.9 \mathrm{~Hz}, 1 \mathrm{H}, \mathrm{H}-2\right), 8.76$ $(\mathrm{d}, J=8.6 \mathrm{~Hz}, 1 \mathrm{H}, \mathrm{H}-6), 8.56(\mathrm{dd}, J=8.5,1.8 \mathrm{~Hz}, 1 \mathrm{H}, \mathrm{H}-4), 7.43(\mathrm{dd}, J=8.3,4.2 \mathrm{~Hz}, 1 \mathrm{H}$, H-3), $6.84(\mathrm{~d}, J=8.6 \mathrm{~Hz}, 1 \mathrm{H}, \mathrm{H}-7), 5.76\left(\mathrm{~d}, J=2.2 \mathrm{~Hz}, 1 \mathrm{H}, \mathrm{H}-3^{\prime}\right), 3.98(\mathrm{~s}, 3 \mathrm{H}, \mathrm{OMe}), 3.52(\mathrm{~m}$, $\left.1 \mathrm{H}, \mathrm{H}-10^{\prime}\right), 2.88\left(\mathrm{~m}, 1 \mathrm{H}, \mathrm{H}-10^{\prime}\right), 2.54\left(\mathrm{~m}, 1 \mathrm{H}, \mathrm{H}-6^{\prime}\right), 2.41\left(\mathrm{~m}, 1 \mathrm{H}, \mathrm{H}-4^{\prime}\right), 2.09\left(\mathrm{~m}, 1 \mathrm{H}, \mathrm{H}-1^{\prime}\right)$, 2.01-1.88 (m, 2H, H-5' , H4' $), 1.46\left(\mathrm{~d}, J=10.0 \mathrm{~Hz}, 1 \mathrm{H}, \mathrm{H}-6^{\prime}\right), 1.29$ (s, 3H, H-9'), 0.80 (s, 3H, $\left.\mathrm{H}-8^{\prime}\right) .{ }^{13} \mathrm{C}-\mathrm{NMR}\left(126 \mathrm{MHz}, \mathrm{CDCl}_{3}\right) \delta 165.2(\mathrm{C}=\mathrm{O}), 149.8(\mathrm{C}-5), 148.5(\mathrm{C}-2), 139.2\left(\mathrm{C}-2^{\prime}\right)$, 131.3 (C-6), 128.7 (C-8), 120.7 (C-7), 120.6 (C-8a), 117.2 (C-4a), $116.2\left(\mathrm{C}-3^{\prime}\right), 116.0$ (C-3), 104.6 (C-4), $55.9(\mathrm{OMe}), 53.9\left(\mathrm{C}-1^{\prime}\right), 41.1\left(\mathrm{C}-10^{\prime}\right), 40.7\left(\mathrm{C}-5^{\prime}\right), 27.4\left(\mathrm{C}-6^{\prime}\right), 26.3\left(\mathrm{C}-9^{\prime}\right), 23.9\left(\mathrm{C}-7^{\prime}\right)$, $22.4\left(\mathrm{C}-4^{\prime}\right), 22.30\left(\mathrm{C}-8^{\prime}\right)$. HRMS: $[\mathrm{M}+\mathrm{H}]^{+}: 337.1916 \mathrm{~m} / \mathrm{z}$ calculated for $\mathrm{C}_{21} \mathrm{H}_{25} \mathrm{~N}_{2} \mathrm{O}_{2}$, found $337.1916 \mathrm{~m} / \mathrm{z}$.

\subsection{Synthesis of 2-(6,6-dimethylbicyclo[3.1.1]hept-2-en-2-yl)-N-(quinolin-8-yl) Acetamide} (3 and 4)

Compounds 3 and $\mathbf{4}$ were synthesized as described for $\mathbf{1}$ and $\mathbf{2}$ above and separated by preparative TLC $\left(85: 1 \mathrm{CHCl}_{3}\right.$ /ethyl acetate, $\mathrm{R}_{\mathrm{f}}=0.81$ (3) and 0.85 (4)) with $25 \%$ yield. 8-Aminoquinoline was obtained from Oakwood Chemicals, Estill, SC, USA.

\subsubsection{Compound 3}

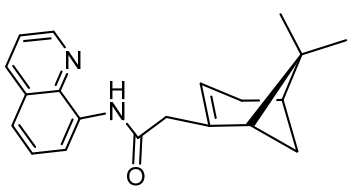

${ }^{1} \mathrm{H}-\mathrm{NMR}\left(500 \mathrm{MHz} \mathrm{CDCl}_{3}\right) \delta 10.06$ (s, 1H, NH), 8.78 (m, 1H, H-2), 8.76 (d, J = 7.8 Hz, $1 \mathrm{H}, \mathrm{H}-4), 8.14(\mathrm{dd}, J=8.2,1.7 \mathrm{~Hz}, 1 \mathrm{H}, \mathrm{H}-5), 7.53$ (t, $J=7.8 \mathrm{~Hz}, 1 \mathrm{H}, \mathrm{H}-6), 7.48$ (dd, $J=8.3$, 
$1.6 \mathrm{~Hz}, 1 \mathrm{H}, \mathrm{H}-7), 7.43$ (dd, J = 8.3, 4.2 Hz, 1H, H-3), 5.67 (s, 1H, H-3'), 3.34 (m, 1H, H-10'), $3.16\left(\mathrm{dd}, J=15.3,1.8 \mathrm{~Hz}, 1 \mathrm{H}, \mathrm{H}-10^{\prime}\right), 2.45\left(\mathrm{~m}, 1 \mathrm{H}, \mathrm{H}-4^{\prime}\right), 2.40\left(\mathrm{~m}, 1 \mathrm{H}, \mathrm{H}-6^{\prime}\right), 2.32(\mathrm{~m}, 1 \mathrm{H}$, $\left.\mathrm{H}-4^{\prime}\right), 2.22\left(\mathrm{~d}, J=5.6 \mathrm{~Hz}, 1 \mathrm{H}, \mathrm{H}-1^{\prime}\right), 2.12\left(\mathrm{~s}, 1 \mathrm{H}, \mathrm{H}-5^{\prime}\right), 1.48\left(\mathrm{~d}, J=8.8 \mathrm{~Hz}, 1 \mathrm{H}, \mathrm{H}-6^{\prime}\right), 1.26(\mathrm{~s}$, 3H, H-9'), 0.85 (s, 3H, H-8'). ${ }^{13} \mathrm{C}-\mathrm{NMR}\left(126 \mathrm{MHz}, \mathrm{CDCl}_{3}\right) \delta 169.6$ (C=O), $148.3(\mathrm{C}-2), 142.2$ (C-2'), 138.6 (C-8), 136.4 (C-5), 134.7 (C-8a), 128.0 (C-4a), 127.7 (C-6), 122.6 (C-7), 121.7 (C-3), 121.5 (C-4), $116.5\left(\mathrm{C}-3^{\prime}\right), 47.2\left(\mathrm{C}-1^{\prime}\right), 46.0\left(\mathrm{C}-10^{\prime}\right), 40.5\left(\mathrm{C}-5^{\prime}\right), 38.3\left(\mathrm{C}-6^{\prime}\right), 32.1\left(\mathrm{C}-4^{\prime}\right), 31.8$ $\left(\mathrm{C}-7^{\prime}\right), 26.2\left(\mathrm{C}-9^{\prime}\right), 21.1\left(\mathrm{C}-8^{\prime}\right)$. HRMS: $[\mathrm{M}+\mathrm{H}]^{+}: 307.1810 \mathrm{~m} / z$ calculated for $\mathrm{C}_{20} \mathrm{H}_{23} \mathrm{~N}_{2} \mathrm{O}$, found $307.1804 \mathrm{~m} / \mathrm{z}$.

\subsubsection{Compound 4}<smiles>CC1(C)C2CCC1C(CC(=O)Nc1cccc3cccnc13)C2</smiles>

${ }^{1} \mathrm{H}-\mathrm{NMR}\left(500 \mathrm{MHz}, \mathrm{CDCl}_{3}\right) \delta 9.74(\mathrm{~s}, 1 \mathrm{H}, \mathrm{NH}), 8.85(\mathrm{~d}, J=7.8 \mathrm{~Hz}, 1 \mathrm{H}, \mathrm{H}-2), 8.80(\mathrm{dd}$, $J=4.3,1.7 \mathrm{~Hz}, 1 \mathrm{H}, \mathrm{H}-4), 8.16(\mathrm{dd}, J=8.3,1.7 \mathrm{~Hz}, 1 \mathrm{H}, \mathrm{H}-5), 7.54(\mathrm{t}, J=7.9 \mathrm{~Hz}, 1 \mathrm{H}, \mathrm{H}-6)$, 7.49-7.47 (m, 1H, H-7), 7.45 (dd, J = 8.2, 4.2 Hz, 1H, H-3), $5.80\left(\mathrm{~s}, 1 \mathrm{H}, \mathrm{H}-3^{\prime}\right), 3.55-3.48(\mathrm{~m}$, $\left.1 \mathrm{H}, \mathrm{H}-10^{\prime}\right), 2.92-2.82\left(\mathrm{~m}, 1 \mathrm{H}, \mathrm{H}-10^{\prime}\right), 2.57\left(\mathrm{~m}, 1 \mathrm{H}, \mathrm{H}-6^{\prime}\right), 2.42\left(\mathrm{~m}, 1 \mathrm{H}, \mathrm{H}-4^{\prime}\right), 2.09(\mathrm{~m}, 1 \mathrm{H}$, $\left.\mathrm{H}-1^{\prime}\right), 1.99\left(\mathrm{~m}, 1 \mathrm{H}, \mathrm{H}-5^{\prime}\right), 1.93\left(\mathrm{~m}, 1 \mathrm{H}, \mathrm{H}-4^{\prime}\right), 1.46\left(\mathrm{~d}, J=9.9 \mathrm{~Hz}, 1 \mathrm{H}, \mathrm{H}-6^{\prime}\right), 1.29\left(\mathrm{~s}, 3 \mathrm{H}, \mathrm{H}-9^{\prime}\right)$, $0.81\left(\mathrm{~s}, 3 \mathrm{H}, \mathrm{H}-8^{\prime}\right) .{ }^{13} \mathrm{C}-\mathrm{NMR}\left(126 \mathrm{MHz}, \mathrm{CDCl}_{3}\right) \delta 166.4(\mathrm{C}=\mathrm{O}), 165.5(\mathrm{C}-2), 148.1\left(\mathrm{C}-2^{\prime}\right), 138.6$ (C-8), 136.5 (C-5), 135.3 (C-8a), 128.1 (C-4a), 127.7 (C-6), 121.6 (C-7), 121.1 (C-3), 116.1 (C-3'), $115.9(\mathrm{C}-4), 54.0\left(\mathrm{C}-1^{\prime}\right), 41.2\left(\mathrm{C}-5^{\prime}\right), 40.7\left(\mathrm{C}-10^{\prime}\right), 27.4\left(\mathrm{C}-6^{\prime}\right), 26.3\left(\mathrm{C}-9^{\prime}\right), 23.9\left(\mathrm{C}-7^{\prime}\right), 22.5\left(\mathrm{C}-4^{\prime}\right)$, $22.3\left(\mathrm{C}-8^{\prime}\right)$. HRMS: $[\mathrm{M}+\mathrm{H}]^{+}: 307.1810 \mathrm{~m} / z$ calculated for $\mathrm{C}_{20} \mathrm{H}_{23} \mathrm{~N}_{2} \mathrm{O}$, found $307.1803 \mathrm{~m} / z$.

3.5. Synthesis of 2-((1S,5R)-6,6-dimethylbicyclo[3.1.1]hept-2-en-2-yl)-N-(quinolin-4-yl) Acetamide (5)

Compound $\mathbf{5}$ was synthesized as described for $\mathbf{1}$ and $\mathbf{2}$ above and separated by preparative TLC (20:1 $\mathrm{CHCl}_{3}$ /ethyl acetate, $\left.\mathrm{R}_{\mathrm{f}}=0.55\right)$ and $25 \%$ yield. 4-Aminoquinoline ( $95 \%$ purity) was obtained from Ark Pharm, Inc., Arlington Heights, IL, USA.

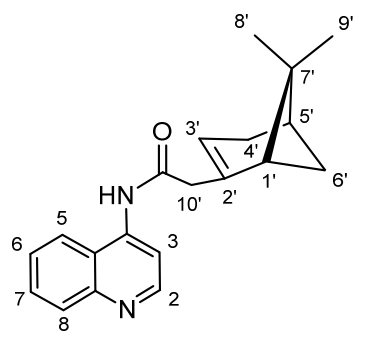

${ }^{1} \mathrm{H}-\mathrm{NMR}\left(500 \mathrm{MHz}, \mathrm{CDCl}_{3}\right) \delta 8.85(\mathrm{~d}, J=5.2 \mathrm{~Hz}, 1 \mathrm{H}, \mathrm{H}-2), 8.34(\mathrm{~d}, J=5.2 \mathrm{~Hz}, 1 \mathrm{H}$, H-3), $8.14(\mathrm{~d}, J=8.4 \mathrm{~Hz}, 1 \mathrm{H}, \mathrm{H}-5), 7.74(\mathrm{~m}, 1 \mathrm{H}, \mathrm{H}-6), 7.73-7.69(\mathrm{~m}, 1 \mathrm{H}, \mathrm{H}-8), 7.58(\mathrm{t}, J=7.58$ $\mathrm{Hz}, 1 \mathrm{H}, \mathrm{H}-7), 5.77\left(\mathrm{~s}, 1 \mathrm{H}, \mathrm{H}-3^{\prime}\right), 3.37\left(\mathrm{~d}, J=15.5 \mathrm{~Hz}, 1 \mathrm{H}, \mathrm{H}-10^{\prime}\right), 3.18(\mathrm{~d}, J=15.4 \mathrm{~Hz}, 1 \mathrm{H}$, H-10'), 2.53-2.48 (m, 1H, H-6 $\left.6^{\prime}\right), 2.47\left(\mathrm{~m}, 1 \mathrm{H}, \mathrm{H}-5^{\prime}\right), 2.42-2.36\left(\mathrm{~m}, 1 \mathrm{H}, \mathrm{H}-4^{\prime}\right), 2.25-2.16(\mathrm{~m}, 2 \mathrm{H}$, H-4') 2.19 (s, 1H, H-6'), 1.29 (s, 3H, H-9'), 1.26 (m, 1H, H-6 $\left.{ }^{\prime}\right), 0.86$ (s, 3H, H-8'). ${ }^{13}$ C-NMR $\left(126 \mathrm{MHz}, \mathrm{CDCl}_{3}\right) \delta 169.4(\mathrm{C}=\mathrm{O}), 151.2(\mathrm{C}-2), 142.7\left(\mathrm{C}-2^{\prime}\right), 140.3$ (C-4a), 130.5 (C-8a), 129.4 (C-5), 126.6 (C-6), 123.6 (C-7), 119.7 (C-3), 118.6 (C-3'), 113.3 (C-8), 110.3 (C-4), 47.0 (C-1'), $45.8\left(\mathrm{C}-10^{\prime}\right), 40.3\left(\mathrm{C}-5^{\prime}\right), 38.2\left(\mathrm{C}-6^{\prime}\right), 32.5\left(\mathrm{C}-4^{\prime}\right), 31.7\left(\mathrm{C}-7^{\prime}\right), 26.1\left(\mathrm{C}-9^{\prime}\right), 21.1\left(\mathrm{C}-8^{\prime}\right)$. HRMS: $[\mathrm{M}-\mathrm{H}]^{-}: 305.1654 \mathrm{~m} / z$ calculated for $\mathrm{C}_{20} \mathrm{H}_{21} \mathrm{~N}_{2} \mathrm{O}$, found $305.1655 \mathrm{~m} / z$. 
3.6. Synthesis of N-(7-chloroquinolin-4-yl)-2-((1S,5R)-6,6-dimethylbicyclo[3.1.1]hept-2-en-2-yl) Acetamide (6)

Compound $\mathbf{6}$ was synthesized as described for 1 and 2 above and separated by preparative TLC (20:1 hexane/ethyl acetate, $\left.\mathrm{R}_{\mathrm{f}}=0.78\right)$ and $36 \%$ yield. $7-$ Chloro-4-aminoquinoline ( $95 \%$ purity) was obtained from Life Chemicals, Ontario, Canada.<smiles>CC1(C)C2CCC1CC(C(=O)Nc1ccnc3cc(Cl)ccc13)C2</smiles>

${ }^{1} \mathrm{H}-\mathrm{NMR}\left(500 \mathrm{MHz}, \mathrm{CDCl}_{3}\right) \delta 8.83(\mathrm{~d}, J=5.1 \mathrm{~Hz}, 1 \mathrm{H}, \mathrm{H}-2), 8.31(\mathrm{~d}, J=5.2 \mathrm{~Hz}, 1 \mathrm{H}, \mathrm{H}-3)$, $8.11(\mathrm{~s}, J=2.1 \mathrm{~Hz}, 1 \mathrm{H}, \mathrm{H}-8), 7.65(\mathrm{~d}, J=9.0 \mathrm{~Hz}, 1 \mathrm{H}, \mathrm{H}-5), 7.52(\mathrm{dd}, J=9.0,2.1 \mathrm{~Hz}, 1 \mathrm{H}, \mathrm{H}-6)$, 5.79-5.75 (m, 1H, H-3'), $3.37\left(\mathrm{~d}, J=16.6 \mathrm{~Hz}, 1 \mathrm{H}, \mathrm{H}-10^{\prime}\right), 3.18\left(\mathrm{~d}, J=17.5 \mathrm{~Hz}, 1 \mathrm{H}, \mathrm{H}-10^{\prime}\right)$, 2.54-2.49 (m, 1H, H-6' $), 2.49-2.44\left(\mathrm{~m}, 1 \mathrm{H}, \mathrm{H}-5^{\prime}\right), 2.38\left(\mathrm{~m}, 1 \mathrm{H}, \mathrm{H}-1^{\prime}\right), 2.21\left(\mathrm{~m}, 2 \mathrm{H}, \mathrm{H}-4^{\prime}\right), 1.29$ $\left(\mathrm{s}, 3 \mathrm{H}, \mathrm{H}-9^{\prime}\right), 1.23\left(\mathrm{~d}, J=8.8 \mathrm{~Hz}, 1 \mathrm{H}, \mathrm{H}-6^{\prime}\right), 0.86\left(\mathrm{~s}, 3 \mathrm{H}, \mathrm{H}-8^{\prime}\right) .{ }^{13} \mathrm{C}-\mathrm{NMR}\left(126 \mathrm{MHz}, \mathrm{CDCl}_{3}\right) \delta$ $169.5(\mathrm{C}=\mathrm{O}), 152.4$ (C-2), 142.8 (C-2'), 138.7 (C-4a) 136.7 (C-7), 135.6 (C-8), 129.5 (C-8a), 127.6 (C-5), 123.9 (C-6), 120.5 (C-3), $118.3\left(\mathrm{C}-3^{\prime}\right), 110.7(\mathrm{C}-4), 47.1\left(\mathrm{C}-1^{\prime}\right), 45.9\left(\mathrm{C}-10^{\prime}\right), 40.4\left(\mathrm{C}-5^{\prime}\right)$, $38.3\left(\mathrm{C}-6^{\prime}\right), 32.7\left(\mathrm{C}-4^{\prime}\right), 31.9\left({\mathrm{C}-7^{\prime}}^{\prime}\right), 26.1\left(\mathrm{C}-9^{\prime}\right), 21.2\left(\mathrm{C}-8^{\prime}\right)$. HRMS: [M - H] ${ }^{-}: 339.1264 \mathrm{~m} / \mathrm{z}$ calculated for $\mathrm{C}_{20} \mathrm{H}_{20} \mathrm{ClN}_{2} \mathrm{O}$, found $339.1263 \mathrm{~m} / z$.

3.7. Synthesis of quinolin-4-yl-2-((1S,5R)-6,6-dimethylbicyclo[3.1.1]hept-2-en-2-yl) Acetate (7)<smiles>CC1(C)C2CCC1C(CC(=O)Oc1ccnc3ccccc13)C2</smiles>

$\mathrm{N}$-(3-Dimethylaminopropyl)- $\mathrm{N}^{\prime}$-ethylcarbodiimide hydrochloride (EDCI, Sigma-Aldrich, 99\% purity, $171.7 \mathrm{mg}, 0.90 \mathrm{mmol}, 1.3 \mathrm{eq}$.), DMAP (4-Dimethylaminopyridine, 99\%, ACROS Organics ${ }^{\mathrm{TM}}, 98.5 \%$ purity, $25.7 \mathrm{mg}, 0.21 \mathrm{mmol}, 0.5$ eq. $)$, and DIEA $(2.04 \mathrm{mmol}, 0.36 \mathrm{~mL}$, and 3eq.) were added to a solution of 4-hydroxyquinoline (100 mg, $0.68 \mathrm{mmol}, 1.0$ eq., Ark Pharm, Inc., $97 \%$ purity) and nopoic acid ( $0.42 \mathrm{mmol}, 1.2 \mathrm{eq}$.) in tetrahydrofuran (THF, Fisher Scientific, $99.9 \%, 2.0 \mathrm{~mL}$ ) at $0{ }^{\circ} \mathrm{C}$ and stirred for $15 \mathrm{~min}$. [25]. The temperature was raised to $23{ }^{\circ} \mathrm{C}$, and the reaction mixture was stirred for $3 \mathrm{~h}$ while monitoring by analytical TLC. The reaction appeared cloudy at first but after stirring for $1 \mathrm{~h}$ at room temperature, it became clear, with the formation of colorless solid precipitate. The reaction mixture was quenched with brine, extracted with EtOAc, concentrated, and separated by preparative TLC (20:1 $\mathrm{CHCl}_{3}$ /ethyl acetate, $\left.\mathrm{R}_{\mathrm{f}}=0.55\right)$ with $25 \%$ yield .

${ }^{1} \mathrm{H}-\mathrm{NMR}\left(500 \mathrm{MHz}, \mathrm{CD}_{3} \mathrm{OD}\right) \delta 8.84(\mathrm{~d}, J=5.0 \mathrm{~Hz}, 1 \mathrm{H}, \mathrm{H}-2), 8.05(\mathrm{~d}, J=8.5 \mathrm{~Hz}, 1 \mathrm{H}$, H-8), $8.02(\mathrm{~d}, J=8.5,1.4 \mathrm{~Hz}, 1 \mathrm{H}, \mathrm{H}-5), 7.81$ (ddd, $J=8.4,6.9,1.4 \mathrm{~Hz}, 1 \mathrm{H}, \mathrm{H}-6), 7.64$ (ddd, $J=8.2,6.8,1.2 \mathrm{~Hz}, 1 \mathrm{H}, \mathrm{H}-7), 7.44(\mathrm{~d}, J=5.0 \mathrm{~Hz}, 1 \mathrm{H}, \mathrm{H}-3), 5.97\left(\mathrm{~m}, 1 \mathrm{H}, \mathrm{H}-3^{\prime}\right), 3.34-3.28(\mathrm{~m}$, $\left.1 \mathrm{H}, \mathrm{H}-10^{\prime}\right), 2.82-2.70\left(\mathrm{~m}, 2 \mathrm{H}, \mathrm{H}-10^{\prime}, \mathrm{H}-1^{\prime}\right), 2.52\left(\mathrm{~m}, 1 \mathrm{H}, \mathrm{H}-6^{\prime}\right), 2.11\left(\mathrm{~m}, 1 \mathrm{H}, \mathrm{H}-5^{\prime}\right), 2.02(\mathrm{~m}, 1 \mathrm{H}$, H-4') $1.96\left(\mathrm{~m}, 1 \mathrm{H}, \mathrm{H}-4^{\prime}\right), 1.48$ (d, J = $\left.10.2 \mathrm{~Hz}, 1 \mathrm{H}, \mathrm{H}-6^{\prime}\right), 1.34$ (s, 3H, H-9'), 0.84 (s, 3H, H-8'). ${ }^{13} \mathrm{C}-\mathrm{NMR}\left(126 \mathrm{MHz}, \mathrm{CD}_{3} \mathrm{OD}\right) \delta 177.2(\mathrm{C}=\mathrm{O}), 164.3$ (C-4a), 156.5 (C-2), 151.9 (C-7), 150.5 (C-2), 131.7 (C-8), 129.2 (C-8a), 124.2 (C-6), $122.8(\mathrm{C}-3), 114.6\left(\mathrm{C}-3^{\prime}\right), 111.4\left(\mathrm{C}-4^{\prime}\right), 42.1\left(\mathrm{C}-1^{\prime}\right)$, $41.6\left(\mathrm{C}-10^{\prime}\right), 34.7\left(\mathrm{C}-5^{\prime}\right), 28.0\left(\mathrm{C}-6^{\prime}\right), 26.7\left(\mathrm{C}-4^{\prime}\right), 26.4\left(\mathrm{C}-7^{\prime}\right), 26.1\left(\mathrm{C}-9^{\prime}\right), 24.5\left(\mathrm{C}-8^{\prime}\right) .[\mathrm{M}+\mathrm{H}]^{+}$: $308.1650 \mathrm{~m} / z$ calculated for $\mathrm{C}_{20} \mathrm{H}_{22} \mathrm{NO}_{2}$, found $308.1651 \mathrm{~m} / \mathrm{z}$. 
3.8. Synthesis of 7-chloroquinolin-4-yl-2-((1S,5R)-6,6-dimethylbicyclo[3.1.1]hept-2-en-2-yl) Acetate (8)

Compound $\mathbf{8}$ was synthesized as described for $\mathbf{7}$ above and separated by preparative TLC (20:1 hexane/ethyl acetate and $R_{\mathrm{f}}=0.85$ ) with $40 \%$ yield. 7-Chloro-4-hydroxyquinoline ( $99 \%$ purity) was obtained from Sigma-Aldrich.<smiles>CC1(C)C2CCC1CC(C(=O)Oc1ccnc3cc(Cl)ccc13)C2</smiles>

${ }^{1} \mathrm{H}-\mathrm{NMR}\left(500 \mathrm{MHz},\left(\mathrm{CD}_{3}\right)_{2} \mathrm{CO}\right) \delta 8.95(\mathrm{~d}, J=4.8 \mathrm{~Hz}, 1 \mathrm{H}, \mathrm{H}-2), 8.10(\mathrm{~d}, J=2.2 \mathrm{~Hz}, 1 \mathrm{H}$, $\mathrm{H}-8), 8.06(\mathrm{~d}, J=9.0 \mathrm{~Hz}, 1 \mathrm{H}, \mathrm{H}-5), 7.62(\mathrm{dd}, J=8.9,2.0 \mathrm{~Hz}, 1 \mathrm{H}, \mathrm{H}-6), 7.49(\mathrm{~d}, J=4.9 \mathrm{~Hz}$, $1 \mathrm{H}, \mathrm{H}-3), 5.99\left(\mathrm{~m}, 1 \mathrm{H}, \mathrm{H}-3^{\prime}\right), 3.31$ (dd, $\left.J=20.4,9.2 \mathrm{~Hz}, 1 \mathrm{H}, \mathrm{H}-10^{\prime}\right), 2.84-2.78\left(\mathrm{~m}, 1 \mathrm{H}, \mathrm{H}-10^{\prime}\right)$, $2.75\left(\mathrm{~m}, 1 \mathrm{H}, \mathrm{H}-\mathrm{1}^{\prime}\right), 2.51\left(\mathrm{dt}, J=10.8,5.8 \mathrm{~Hz}, 1 \mathrm{H}, \mathrm{H}-6^{\prime}\right), 2.14-2.10\left(\mathrm{~m}, 1 \mathrm{H}, \mathrm{H}-5^{\prime}\right), 2.02(\mathrm{ddt}$, $\left.J=10.1,3.9,1.9 \mathrm{~Hz}, 1 \mathrm{H}, \mathrm{H}-4^{\prime}\right), 1.94\left(\mathrm{~m}, 1 \mathrm{H}, \mathrm{H}-4^{\prime}\right), 1.49\left(\mathrm{~d}, J=10.1 \mathrm{~Hz}, 1 \mathrm{H}, \mathrm{H}-6^{\prime}\right), 1.33$ (s, 3H, H-9'), $0.84\left(\mathrm{~s}, 3 \mathrm{H}, \mathrm{H}-8^{\prime}\right) .{ }^{13} \mathrm{C}-\mathrm{NMR}\left(126 \mathrm{MHz},\left(\mathrm{CD}_{3}\right)_{2} \mathrm{CO}\right) \delta 176.1(\mathrm{C}=\mathrm{O}), 163.4(\mathrm{C}-4 \mathrm{a})$, 155.3 (C-2), 153.4 (C-7), 151.2 (C-2'), 136.1 (C-8), 129.0 (C-8a), 128.3 (C-5), 124.5 (C-6), 122.2 (C-3), $114.6\left(\mathrm{C}-3^{\prime}\right), 111.3(\mathrm{C}-4), 54.7\left(\mathrm{C}-1^{\prime}\right), 41.7\left(\mathrm{C}-10^{\prime}\right), 41.1\left(\mathrm{C}-5^{\prime}\right), 27.6\left(\mathrm{C}-6^{\prime}\right), 26.2\left(\mathrm{C}-9^{\prime}\right)$, $24.1\left(\mathrm{C}-4^{\prime}\right), 23.6\left(\mathrm{C}-7^{\prime}\right), 22.4\left(\mathrm{C}-8^{\prime}\right) .[\mathrm{M}+\mathrm{H}]^{+}: 342.1261 \mathrm{~m} / z$ for calculated $\mathrm{C}_{20} \mathrm{H}_{21} \mathrm{ClNO}_{2}$, found $342.1259 \mathrm{~m} / \mathrm{z}$.

3.9. Synthesis of 7-chloro-2,8-dimethylquinolin-4-yl-2-((1S,5R)-6,6-dimethylbicyclo[3.1.1]hept-2 -en-2-yl) Acetate (9)

Compound 9 was synthesized as described for 7 above and separated by preparative TLC ( $4: 1$ hexane/ethyl acetate, $\left.R_{f}=0.89\right)$ with $39 \%$ yield. 7 -Chloro-2,8-dimethyl-4hydroxyquinoline ( $98 \%$ purity) was obtained from Sigma-Aldrich.<smiles></smiles>

${ }^{1} \mathrm{H}-\mathrm{NMR}\left(500 \mathrm{MHz},\left(\mathrm{CD}_{3}\right)_{2} \mathrm{CO}\right) \delta 7.78(\mathrm{~d}, J=9.0 \mathrm{~Hz}, 1 \mathrm{H}, \mathrm{H}-6), 7.50(\mathrm{~d}, J=8.9 \mathrm{~Hz}, 1 \mathrm{H}$, H-5), 7.31 (s, 1H, H-3), 5.96 (m, 1H, H-3'), 3.34-3.27 (m, 1H, H-10'), 2.82 (s, 3H, C-3Me), $2.77\left(\mathrm{~m}, 1 \mathrm{H}, \mathrm{H}-10^{\prime}\right) 2.74\left(\mathrm{~m}, 1 \mathrm{H}, \mathrm{H}-1^{\prime}\right), 2.71(\mathrm{~s}, 3 \mathrm{H}, \mathrm{C}-8 \mathrm{Me}), 2.51\left(\mathrm{~m}, 1 \mathrm{H}, \mathrm{H}-6^{\prime}\right), 2.11(\mathrm{~m}, 1 \mathrm{H}$, H-5'), 2.03-1.99 (m, 1H, H-4'), 1.97-1.91 (m, 1H, H-4'), 1.48 (d, J = 10.1 Hz, 1H, H-6'), 1.33 (s, $\left.3 \mathrm{H}, \mathrm{H}-9^{\prime}\right), 0.83$ (s, 3H, H-8'). ${ }^{13} \mathrm{C}-\mathrm{NMR}\left(126 \mathrm{MHz}\left(\mathrm{CD}_{3}\right)_{2} \mathrm{CO}\right) \delta 175.6(\mathrm{C}=\mathrm{O}), 163.5$ (C-4a), 160.8 (C-2), 155.6 (C-7), 149.6 (C-2'), 135.6 (C-8), 134.9 (C-8a), 127.6 (C-5), 120.9 (C-6), 120.5 (C-3), $114.6\left(\mathrm{C}-3^{\prime}\right), 111.4(\mathrm{C}-4), 54.7\left(\mathrm{C}-1^{\prime}\right), 41.7\left(\mathrm{C}-10^{\prime}\right), 41.1\left(\mathrm{C}-5^{\prime}\right), 27.6\left(\mathrm{C}-6^{\prime}\right), 26.2\left(\mathrm{C}-9^{\prime}\right)$, $25.8\left(\mathrm{C}-4^{\prime}\right), 24.1(\mathrm{C}-2 \mathrm{Me}), 23.5\left(\mathrm{C}-7^{\prime}\right), 22.4\left(\mathrm{C}-8^{\prime}\right), 14.7(\mathrm{C}-8 \mathrm{Me})$. [M $\left.+\mathrm{H}\right]^{+}: 370.1574 \mathrm{~m} / z$ for calculated $\mathrm{C}_{22} \mathrm{H}_{25} \mathrm{ClNO}_{2}$, found $370.1574 \mathrm{~m} / z$.

3.10. Synthesis of 6-fluoro-2-(trifluoromethyl)quinolin-4-yl-2-((1S,5R)-6,6-dimethylbicyclo [3.1.1] hept-2-en-2yl) Acetate (10)

Compound 10 was synthesized as described for 7 above and separated by preparative TLC (4.5:1 hexane/ethyl acetate, $\left.R_{f}=0.78\right)$ with $33 \%$ yield. 6-Fluoro-4-hydroxy-2(trifluoromethyl)quinoline (98\% purity) was obtained from Sigma-Aldrich. 
<smiles>CC1(C)C2CCC1CC(C(=O)Oc1cc(C(F)(F)F)nc3ccc(F)cc13)C2</smiles>

${ }^{1} \mathrm{H}-\mathrm{NMR}\left(500 \mathrm{MHz}, \mathrm{CDCl}_{3}\right) \delta 8.25$ (m, 1H, H-7), 7.78 (s, 1H, H-3), 7.67 (m, 1H, H-8), $7.60(\mathrm{~s}, 1 \mathrm{H}, \mathrm{H}-5), 5.91\left(\mathrm{~s}, 1 \mathrm{H}, \mathrm{H}-3^{\prime}\right), 3.33\left(\mathrm{dd}, J=20.5,9.3 \mathrm{~Hz}, 1 \mathrm{H}, \mathrm{H}-10^{\prime}\right), 2.88-2.73(\mathrm{~m}, 1 \mathrm{H}$, $\left.\mathrm{H}-10^{\prime}\right), 2.71\left(\mathrm{t}, J=5.4 \mathrm{~Hz}, 1 \mathrm{H}, \mathrm{H}-1^{\prime}\right), 2.50\left(\mathrm{~m}, 1 \mathrm{H}, \mathrm{H}-6^{\prime}\right), 2.16\left(\mathrm{~m}, 1 \mathrm{H}, \mathrm{H}-5^{\prime}\right), 2.05-1.93(\mathrm{~m}, 2 \mathrm{H}$, $\left.\mathrm{H}-4^{\prime}\right), 1.47\left(\mathrm{~d}, J=10.2 \mathrm{~Hz}, 1 \mathrm{H}, \mathrm{H}-6^{\prime}\right), 1.34\left(\mathrm{~s}, 3 \mathrm{H}, \mathrm{H}-9^{\prime}\right), 0.85\left(\mathrm{~s}, 3 \mathrm{H}, \mathrm{H}-8^{\prime}\right) .{ }^{13} \mathrm{C}-\mathrm{NMR}(126$ $\left.\mathrm{MHz}, \mathrm{CDCl}_{3}\right) \delta 177.7$ (C=O), 162.4 (C-6), 146.2 (C-2), 142.2 (C-2'), 133.1 (C-8), 133.0 (C-4a), $124.2\left(\mathrm{CF}_{3}\right), 121.9$ (C-7), 121.7 (C-8a), 110.1 (C-3'), 109.8 (C-5), 105.8 (C-3), 105.6 (C-4), 54.4 $\left(\mathrm{C}-1^{\prime}\right), 41.4\left(\mathrm{C}-10^{\prime}\right), 40.4\left(\mathrm{C}-5^{\prime}\right), 27.4\left(\mathrm{C}-6^{\prime}\right), 26.2\left(\mathrm{C}-9^{\prime}\right), 23.7\left(\mathrm{C}-4^{\prime}\right), 23.4\left(\mathrm{C}-7^{\prime}\right), 22.4\left(\mathrm{C}-8^{\prime}\right)$. [M $+\mathrm{Na}]^{+}: 416.1250 \mathrm{~m} / z$ calculated for $\mathrm{C}_{21} \mathrm{H}_{19} \mathrm{~F}_{4} \mathrm{NO}_{2} \mathrm{Na}$, found: $416.1245 \mathrm{~m} / z$.

3.11. Synthesis of 7-chloro-8-methylquinolin-4-yl-2-((1S,5R)-6,6-dimethylbicyclo[3.1.1]hept2-en-2-yl) Acetate (11)

Compound 11 was synthesized as described for $\mathbf{7}$ above and separated by preparative TLC (5:1 hexane/ethyl acetate, $\left.R_{\mathrm{f}}=0.82\right)$ with $38 \%$ yield. 7 -Chloro-4-hydroxy-8methylquinoline ( $98 \%$ purity) was obtained from Sigma-Aldrich.<smiles>Cc1c(Cl)ccc2c(OC(=O)C3CCC4CCC3C4(C)C)ccnc12</smiles>

${ }^{1} \mathrm{H}-\mathrm{NMR}\left(500 \mathrm{MHz}, \mathrm{CDCl}_{3}\right) \delta 8.92(\mathrm{~d}, J=4.9 \mathrm{~Hz}, 1 \mathrm{H}, \mathrm{H}-2), 7.79(\mathrm{~d}, J=8.9 \mathrm{~Hz}, 1 \mathrm{H}$, H-6), $7.51(\mathrm{~d}, J=9.0 \mathrm{~Hz}, 1 \mathrm{H}, \mathrm{H}-5), 7.33(\mathrm{~d}, J=4.9 \mathrm{~Hz}, 1 \mathrm{H}, \mathrm{H}-3), 5.90(\mathrm{t}, J=2.3 \mathrm{~Hz}, 1 \mathrm{H}$, H-3'), 3.36-3.27 (m, 1H, H-10'), $2.88(\mathrm{~s}, 3 \mathrm{H}, \mathrm{C}-8 \mathrm{Me}), 2.76\left(\mathrm{~m}, 1 \mathrm{H}, \mathrm{H}-10^{\prime}\right), 2.68(\mathrm{t}, J=5.3 \mathrm{~Hz}$, $\left.1 \mathrm{H}, \mathrm{H}-\mathrm{1}^{\prime}\right), 2.48\left(\mathrm{~m}, 1 \mathrm{H}, \mathrm{H}-6^{\prime}\right), 2.13\left(\mathrm{~s}, 1 \mathrm{H}, \mathrm{H}-5^{\prime}\right), 2.03-1.98\left(\mathrm{~m}, 1 \mathrm{H}, \mathrm{H}-4^{\prime}\right), 1.93\left(\mathrm{~m}, 1 \mathrm{H}, \mathrm{H}-4^{\prime}\right)$, $1.46\left(\mathrm{~d}, J=10.1 \mathrm{~Hz}, 1 \mathrm{H}, \mathrm{H}-6^{\prime}\right), 1.25$ (s, 3H, H-9'), 0.84 (s, 3H, H-8 $) .{ }^{13} \mathrm{C}-\mathrm{NMR}(126 \mathrm{MHz}$, $\left.\mathrm{CDCl}_{3}\right) \delta 175.8(\mathrm{C}=\mathrm{O}), 163.0$ (C-4a), 154.6 (C-2), 150.5 (C-7), 149.8 (C-2'), 135.4 (C-8), 135.0 (C-8a), 128.0 (C-5), 121.0 (C-6), 119.9 (C-3), $112.8\left(\mathrm{C}-3^{\prime}\right), 110.5$ (C-4), $54.2\left(\mathrm{C}-1^{\prime}\right), 41.1\left(\mathrm{C}-10^{\prime}\right)$, $40.35\left(\mathrm{C}-5^{\prime}\right), 31.92\left(\mathrm{C}-7^{\prime}\right), 27.24\left(\mathrm{C}-6^{\prime}\right), 26.02\left(\mathrm{C}-9^{\prime}\right), 23.53\left(\mathrm{C}-4^{\prime}\right), 22.23\left(\mathrm{C}-8^{\prime}\right), 14.77(\mathrm{C}-8 \mathrm{Me})$. $[\mathrm{M}+\mathrm{Na}]^{+}: 378.1237 \mathrm{~m} / z$ for calculated for $\mathrm{C}_{21} \mathrm{H}_{22} \mathrm{ClNO}_{2} \mathrm{Na}$ found $378.1234 \mathrm{~m} / z$.

3.12. Synthesis of 2,8-bis(trifluoromethyl)quinolin-4-yl-2-((1S,5R)-6,6-dimethylbicyclo[3.1.1]hept2-en-2-yl) Acetate (12)

Compound 12 was synthesized as described for 7 above and separated by preparative $\operatorname{TLC}\left(4.5: 1\right.$ hexane/ethyl acetate, $\left.\mathrm{R}_{\mathrm{f}}=0.76\right)$ with $31 \%$ yield. 2,8-Bis(trifluoromethyl)-4quinolinol (99\% purity, Acros Organics) was obtained from Thermo Fisher Scientific, Waltham, MA.<smiles>CC1(C)C2CC=C(CC(=O)Oc3cc(C(F)(F)F)nc4c(C(F)(F)F)cccc34)C1C2</smiles> 
${ }^{1} \mathrm{H}-\mathrm{NMR}\left(500 \mathrm{MHz}, \mathrm{CDCl}_{3}\right) \delta 8.28(\mathrm{~d}, J=8.6 \mathrm{~Hz}, 1 \mathrm{H}, \mathrm{H}-7), 8.18(\mathrm{~d}, J=7.4 \mathrm{~Hz}, \mathrm{H}-5)$, 7.84 (s, 1H, H-3), 7.74-7.67 (m, 1H, H-6), $5.92\left(\mathrm{~s}, 1 \mathrm{H}, \mathrm{H}-3^{\prime}\right), 3.38-3.28$ (m, 1H, H-10'), 2.80 $\left(\mathrm{m}, 1 \mathrm{H}, \mathrm{H}-10^{\prime}\right), 2.71\left(\mathrm{~m}, 1 \mathrm{H}, \mathrm{H}-\mathrm{1}^{\prime}\right), 2.50\left(\mathrm{~m}, 1 \mathrm{H}, \mathrm{H}-6^{\prime}\right), 2.16\left(\mathrm{~m}, 1 \mathrm{H}, \mathrm{H}-5^{\prime}\right), 2.08-2.00(\mathrm{~m}$, $\left.1 \mathrm{H}, \mathrm{H}-4^{\prime}\right), 1.96\left(\mathrm{~m}, 1 \mathrm{H}, \mathrm{H}-4^{\prime}\right), 1.47\left(\mathrm{~d}, J=10.3 \mathrm{~Hz}, 1 \mathrm{H}, \mathrm{H}-6^{\prime}\right), 1.34\left(\mathrm{~s}, 3 \mathrm{H}, \mathrm{H}-9^{\prime}\right), 0.85(\mathrm{~s}, 3 \mathrm{H}$, H-8 $) .{ }^{13} \mathrm{C}-\mathrm{NMR}\left(126 \mathrm{MHz}, \mathrm{CDCl}_{3}\right) \delta 178.0(\mathrm{C}=\mathrm{O}), 162.4$ (C-6), $156.2(\mathrm{C}-2), 149.3$ (C-8a), $145.4\left(\mathrm{C}-2^{\prime}\right), 129.6$ (C-8), 129.6 (C-4a), 127.21 (C-4), $126.3(\mathrm{C}-5), 124.7\left(\mathrm{CF}_{3}\right), 124.0\left(\mathrm{CF}_{3}\right), 122.6$ (C-7), $122.5(\mathrm{C}-3), 110.1\left(\mathrm{C}-3^{\prime}\right), 54.5\left(\mathrm{C}-1^{\prime}\right), 41.4\left(\mathrm{C}-10^{\prime}\right), 40.4\left(\mathrm{C}-5^{\prime}\right), 27.4\left(\mathrm{C}-6^{\prime}\right), 26.2\left(\mathrm{C}-9^{\prime}\right)$, $23.7\left(\mathrm{C}-4^{\prime}\right), 23.5\left(\mathrm{C}-8^{\prime}\right), 22.4\left(\mathrm{C}-8^{\prime}\right) .[\mathrm{M}+\mathrm{Na}]^{+}: 466.1218 \mathrm{~m} / z$ calculated for $\mathrm{C}_{22} \mathrm{H}_{19} \mathrm{~F}_{6} \mathrm{NO}_{2} \mathrm{Na}$, found $466.1220 \mathrm{~m} / \mathrm{z}$.

3.13. Synthesis of 2-((1S,5R)-6,6-dimethylbicyclo[3.1.1]hept-2-en-2-yl)ethyl-7-chloro-2methylquinoline-4-carboxylate (13)

EDCI (112.1 mg, $0.58 \mathrm{mmol}$, and $1.3 \mathrm{eq}$.) was added to a solution of 7-chloro-2 methyl4-quinolinecarboxylic acid ( $99.7 \mathrm{mg}, 0.45 \mathrm{mmol}, 1.0$ eq., Sigma-Aldrich, $98 \%$ purity) in THF $(1.0 \mathrm{~mL})$ at $0{ }^{\circ} \mathrm{C}$ and stirred for $15 \mathrm{~min}$. Nopol $(90.0 \mathrm{mg}, 0.54 \mathrm{mmol}, 1.2 \mathrm{eq}$.) in THF (1.0 mL) was added, followed by DIEA $(2.04 \mathrm{mmol}, 0.36 \mathrm{~mL}, 3 \mathrm{eq}$.). The reaction mixture was stirred at room temperature for $3 \mathrm{~h}$ while monitoring by analytical TLC. The reaction mixture was quenched with brine, extracted with EtOAc, concentrated, and separated by preparative TLC (3:1 hexane/ethyl acetate, $\left.R_{\mathrm{f}}=0.92\right)$ with $35 \%$ yield.<smiles>Cc1cc(C(=O)OCCC2C=CC3CC2C3(C)C)c2ccc(Cl)cc2n1</smiles>

${ }^{1} \mathrm{H}-\mathrm{NMR}\left(500 \mathrm{MHz}, \mathrm{CDCl}_{3}\right) \delta 8.69(\mathrm{dd}, J=9.1,1.5 \mathrm{~Hz}, 1 \mathrm{H}, \mathrm{H}-6), 8.06(\mathrm{~d}, J=1.9 \mathrm{~Hz}$ $1 \mathrm{H}, \mathrm{H}-8), 7.78(\mathrm{~d}, J=1.6 \mathrm{~Hz} 1 \mathrm{H}, \mathrm{H}-3), 7.51(\mathrm{~d}, J=9.1 \mathrm{~Hz}, 1 \mathrm{H}, \mathrm{H}-5), 5.40\left(\mathrm{~m}, 1 \mathrm{H}, \mathrm{H}-3^{\prime}\right), 4.45$ $\left(\mathrm{m}, 2 \mathrm{H}, \mathrm{H}-11^{\prime}\right), 2.77(\mathrm{~d}, J=1.7 \mathrm{~Hz}, 3 \mathrm{H}, \mathrm{C}-2 \mathrm{Me}), 2.49\left(\mathrm{~s}, 2 \mathrm{H}, \mathrm{H}-10^{\prime}\right), 2.43-2.38\left(\mathrm{~m}, 1 \mathrm{H}, \mathrm{H}-6^{\prime}\right)$,

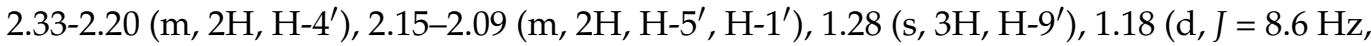
1H, H-6 $\left.{ }^{\prime}\right), 0.85$ (s, 3H, H-8'). ${ }^{13} \mathrm{C}-\mathrm{NMR}(126 \mathrm{MHz}, \mathrm{CDCl} 3) \delta 166.1$ (C=O), 160.0 (C-3), 149.5 (C-2), 144.0 (C-2'), 135.8 (C-8), 135.3 (C-8a), 128.3 (C-5), 128.2 (C-6), 127.1 (C-4), 123.6 (C-4a), $122.0(\mathrm{C}-3), 119.5\left(\mathrm{C}-3^{\prime}\right), 64.3\left(\mathrm{C}-11^{\prime}\right), 45.9\left(\mathrm{C}-10^{\prime}\right), 40.8\left(\mathrm{C}-1^{\prime}\right), 38.2\left(\mathrm{C}-5^{\prime}\right), 36.1\left(\mathrm{C}-7^{\prime}\right), 31.9$ $\left(\mathrm{C}-6^{\prime}\right), 31.6\left(\mathrm{C}-4^{\prime}\right), 26.4\left(\mathrm{C}-9^{\prime}\right), 25.3(\mathrm{C}-2 \mathrm{Me}), 21.3\left(\mathrm{C}-8^{\prime}\right)$. [M + H $]^{+}: 370.1574 \mathrm{~m} / z$ calculated for $\mathrm{C}_{22} \mathrm{H}_{25} \mathrm{ClNO}_{2}$, found $370.1575 \mathrm{~m} / z$.

3.14. Synthesis of 2-((1S,5R)-6,6-dimethylbicyclo[3.1.1]hept-2-en-2-yl)ethyl-2-chloroquinoline3-carboxylate (14)

Compound 14 was synthesized as described for $\mathbf{1 3}$ above and separated by preparative TLC preparative TLC by preparative TLC $\left(40: 1 \mathrm{CHCl}_{3} / \mathrm{Et}_{2} \mathrm{O}, \mathrm{R}_{\mathrm{f}}=0.72\right)$ with $50 \%$ yield. The acid, 2-chloroquinoline-3-carboxylic acid (97\% purity) was obtained from Sigma-Aldrich.<smiles>CC1(C)C2C=CC1C(CCOC(=O)c1cc3ccccc3nc1Cl)C2</smiles>

${ }^{1} \mathrm{H}-\mathrm{NMR}\left(500 \mathrm{MHz}, \mathrm{CD}_{3} \mathrm{OD}\right) \delta 8.76(\mathrm{~s}, 1 \mathrm{H}, \mathrm{H}-4), 8.01(\mathrm{~d}, J=8.1 \mathrm{~Hz}, 1 \mathrm{H}, \mathrm{H}-5), 7.94(\mathrm{~d}, J$ $=8.5 \mathrm{~Hz}, 1 \mathrm{H}, \mathrm{H}-8), 7.88(\mathrm{dd}, J=8.5,6.9 \mathrm{~Hz}, 1 \mathrm{H}, \mathrm{H}-7), 7.68(\mathrm{t}, J=7.6 \mathrm{~Hz}, 1 \mathrm{H}, \mathrm{H}-6), 5.39(\mathrm{~s}, 1 \mathrm{H}$, 
$\left.\mathrm{H}-3^{\prime}\right), 4.38\left(\mathrm{qt}, J=10.9,6.8 \mathrm{~Hz}, 2 \mathrm{H}, \mathrm{H}-11^{\prime}\right), 2.46\left(\mathrm{~m}, 2 \mathrm{H}, \mathrm{H}-10^{\prime}\right), 2.40(\mathrm{dt}, J=8.7,5.7 \mathrm{~Hz}, 1 \mathrm{H}$, H-6 $\left.{ }^{\prime}\right)$, 2.30-2.17 (m, 2H, H-4 $\left.{ }^{\prime}\right), 2.17-2.12\left(\mathrm{~m}, 1 \mathrm{H}, \mathrm{H}-5^{\prime}\right), 2.06\left(\mathrm{~m}, 1 \mathrm{H}, \mathrm{H}-1^{\prime}\right), 1.27$ (s, 3H, H-9' $)$, $1.17\left(\mathrm{~d}, J=8.6 \mathrm{~Hz}, 1 \mathrm{H}, \mathrm{H}-6^{\prime}\right), 0.84\left(\mathrm{~s}, 3 \mathrm{H}, \mathrm{H}-8^{\prime}\right) .{ }^{13} \mathrm{C}-\mathrm{NMR}\left(126 \mathrm{MHz}, \mathrm{CD}_{3} \mathrm{OD}\right) 165.70(\mathrm{C}=\mathrm{O})$, 149.2 (C-2), 148.4 (C-4a), 145.5 (C-3), 143.0 (C-3'), 134.1 (C-6), 129.9 (C-8), 129.3 (C-8a), 128.7 (C-4), $127.3(\mathrm{C}-5), 125.9(\mathrm{C}-7), 120.2\left(\mathrm{C}-3^{\prime}\right), 65.3\left(\mathrm{C}-11^{\prime}\right), 46.9\left(\mathrm{C}-10^{\prime}\right), 42.0\left(\mathrm{C}-5^{\prime}\right), 38.9\left(\mathrm{C}-1^{\prime}\right)$, $36.9\left(\mathrm{C}-6^{\prime}\right), 32.6\left(\mathrm{C}-7^{\prime}\right), 32.3\left(\mathrm{C}-4^{\prime}\right), 26.7\left(\mathrm{C}-9^{\prime}\right), 21.6\left(\mathrm{C}-8^{\prime}\right) .[\mathrm{M}+\mathrm{H}]^{+}: 356.1417 \mathrm{~m} / z$ calculated for $\mathrm{C}_{21} \mathrm{H}_{23} \mathrm{ClNO}_{2}$, found $356.1409 \mathrm{~m} / \mathrm{z}$.

3.15. Synthesis of 2-((1R,5S)-6,6-dimethylbicyclo[3.1.1]hept-2-en-2-yl)ethyl-1H-indole2-carboxylate (15)

Compound 15 was synthesized as described for $\mathbf{1 3}$ above and separated by preparative TLC (40:1 $\left.\mathrm{CHCl}_{3} / \mathrm{Et}_{2} \mathrm{O}, \mathrm{R}_{\mathrm{f}}=0.72\right)$ with $50 \%$ yield. Indole 2 -carboxylic acid (98\% purity) was obtained from Sigma-Aldrich.

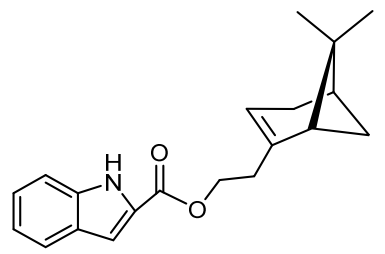

${ }^{1} \mathrm{H}-\mathrm{NMR}\left(500 \mathrm{MHz}, \mathrm{CD}_{3} \mathrm{OD}\right) \delta 7.61(\mathrm{~d}, J=8.1 \mathrm{~Hz}, 1 \mathrm{H}, \mathrm{H}-7), 7.43(\mathrm{~d}, J=8.4 \mathrm{~Hz}, 1 \mathrm{H}$, $\mathrm{H}-4), 7.24$ (t, J = 7.7 Hz, 1H, H-5), $7.11(\mathrm{~s}, 1 \mathrm{H}, \mathrm{H}-3), 7.06$ (t, $J=7.6 \mathrm{~Hz}, 1 \mathrm{H}, \mathrm{H}-6), 5.39(\mathrm{~s}, 1 \mathrm{H}$, H-3' $)$, 4.38-4.27 (m, 2H, H-11' $), 2.47-2.39$ (m, 3H, H-10' $\left.{ }^{\prime} \mathrm{H}_{-} 6^{\prime}\right), 2.31-2.19$ (m, 2H, H-4 $\left.{ }^{\prime}\right), 2.17$ $\left(\mathrm{t}, J=5.6 \mathrm{~Hz}, 1 \mathrm{H}, \mathrm{H}-5^{\prime}\right), 2.07\left(\mathrm{~s}, 1 \mathrm{H}, \mathrm{H}-1^{\prime}\right), 1.28\left(\mathrm{~s}, 3 \mathrm{H}, \mathrm{H}-9^{\prime}\right), 1.19\left(\mathrm{~d}, J=8.6 \mathrm{~Hz}, 1 \mathrm{H}, \mathrm{H}-6^{\prime}\right)$, $0.86\left(\mathrm{~s}, 3 \mathrm{H}, \mathrm{H}-8^{\prime}\right) .{ }^{13} \mathrm{C}-\mathrm{NMR}\left(126 \mathrm{MHz}, \mathrm{CD}_{3} \mathrm{OD}\right) \delta 163.5(\mathrm{C}=\mathrm{O}), 145.8\left(\mathrm{C}^{\prime} 3^{\prime}\right), 139.0(\mathrm{C}-7 \mathrm{a})$, 128.6 (C-3a), 126.0 (C-2), 123.1 (C-4), 121.3 (C-6), 120.2 (C-5), 113.3 (C-2'), 109.2 (C-7), 64.2 $\left(\mathrm{C}-11^{\prime}\right), 47.0\left(\mathrm{C}-10^{\prime}\right), 42.0\left(\mathrm{C}-1^{\prime}\right), 40.0\left(\mathrm{C}-5^{\prime}\right), 37.1\left(\mathrm{C}-7^{\prime}\right), 32.6\left(\mathrm{C}-6^{\prime}\right), 32.4\left(\mathrm{C}-4^{\prime}\right), 26.7\left(\mathrm{C}-9^{\prime}\right)$, 24.2 (C-9), 21.6 (C-8) HRMS: [M + H] $]^{+}: 310.1807 \mathrm{~m} / z$ calculated for $\mathrm{C}_{20} \mathrm{H}_{24} \mathrm{NO}_{2}$, found $310.1806 \mathrm{~m} / \mathrm{z}$.

3.16. Synthesis of 2-((1S,2S,4R,6S)-7,7-dimethyl-3-oxatricyclo[4.1.1.0 2,4]octan-2-yl)ethyl-7chloro-2-methylquinoline-4-carboxylate (16)

Nopol (500 mg, $3.0 \mathrm{mmol}$, 1.eq.) was added to a round $100 \mathrm{~mL}$ bottom flask, followed by $4.0 \mathrm{~mL}$ of ethyl acetate, $4.0 \mathrm{~mL}$ of deionized $\mathrm{H}_{2} \mathrm{O}$, and $8.0 \mathrm{~mL}$ of acetone, and stirred at room temperature. $\mathrm{NaHCO}_{3(\mathrm{~s})}(9.0 \mathrm{mmol}, 756 \mathrm{mg}, 3.0$ eq.) was added to the mixture and stirred for $15 \mathrm{~min}$. Oxone salt (3.6 mmol, $2.4 \mathrm{~g}, 1.2 \mathrm{eq}$.), dissolved in $1.0 \mathrm{~mL}$ of water, was added dropwise for $1 \mathrm{~h}$, and analytical TLC was used to monitor the reaction for 2.5 $h$ [26]. The reaction was quenched with $3.0 \mathrm{~mL}$ of $\mathrm{H}_{2} \mathrm{O}$. The organic layer was extracted with $15.0 \mathrm{~mL} \mathrm{CHCl}_{3}$ (3 times), dried over $\mathrm{MgSO}_{4}$ (s), and concentrated. The crude colorless solid obtained was separated by preparative TLC $\left(10: 1 \mathrm{CHCl}_{3}\right.$ /ethyl acetate, $\left.\mathrm{R}_{\mathrm{f}}=0.37\right)$ with $40 \%$ yield of nopol oxide. EDCI (112.1 mg, $0.58 \mathrm{mmol}, 1.3$ eq.), DMAP (27.5 mg, $0.23 \mathrm{mmol}, 0.5$ eq. $)$, and DIEA (2.04 mmol, $0.36 \mathrm{~mL}, 3$ eq.) were added to a solution of 7-chloro-2-methyl-4-quinolinecarboxylic acid $(99.7 \mathrm{mg}, 0.45 \mathrm{mmol}, 1.0$ eq., Sigma-Aldrich, $98 \%$ ) and nopol oxide (151.9 mg, $0.54 \mathrm{mmol}$, and $1.2 \mathrm{eq}$.) in THF (2.0 mL) at $0{ }^{\circ} \mathrm{C}$ and stirred for $15 \mathrm{~min}$. The temperature was raised to $23^{\circ} \mathrm{C}$, and the mixture was stirred for $3 \mathrm{~h}$ while monitoring by analytical TLC, quenched with brine, extracted with EtOAc, and separated by preparative TLC (4.5:1 hexane/ethyl acetate, $\left.\mathrm{R}_{\mathrm{f}}=0.59\right)$ with $49 \%$ yield.<smiles>Cc1cc(C(=O)OCC[C@]2(O)CC[C@H]3CC2C3(C)C)c2ccc(Cl)cc2n1</smiles> 
${ }^{1} \mathrm{H}-\mathrm{NMR}\left(500 \mathrm{MHz}, \mathrm{CDCl}_{3}\right) \delta 8.68(\mathrm{~d}, J=9.1 \mathrm{~Hz}, 1 \mathrm{H}, \mathrm{H}-5), 8.06(\mathrm{~d}, J=2.2 \mathrm{~Hz}, 1 \mathrm{H}$, H-8), 7.79 (s, 1H, H-3), 7.53 (d, J = 9.1, 2.2 Hz, 1H, H-6), 4.57-4.44 (m, 2H, H-11'), 3.21 (d, $\left.J=4.2,1.5 \mathrm{~Hz}, 1 \mathrm{H}, \mathrm{H}-3^{\prime}\right), 2.78(\mathrm{~s}, 3 \mathrm{H}, \mathrm{C}-2 \mathrm{Me}), 2.29\left(\mathrm{dt}, J=14.8,6.0 \mathrm{~Hz}, 1 \mathrm{H}, \mathrm{H}-6^{\prime}\right), 2.16(\mathrm{~s}$, $\left.1 \mathrm{H}, \mathrm{H}-5^{\prime}\right), 2.08-2.02\left(\mathrm{~m}, 2 \mathrm{H}, \mathrm{H}-4^{\prime}, \mathrm{H}^{\prime} 1^{\prime}\right), 1.94\left(\mathrm{~m}, 1 \mathrm{H}, \mathrm{H}-10^{\prime}\right), 1.77$ (m, 1H, H-10'), $1.67(\mathrm{~d}, J=$ $\left.9.8 \mathrm{~Hz}, 1 \mathrm{H}, \mathrm{H}-6^{\prime}\right), 1.32$ (s, 3H, H-9'), 0.98 (s, 3H, H-8 $) .{ }^{13} \mathrm{C}-\mathrm{NMR}\left(126 \mathrm{MHz}, \mathrm{CDCl}_{3}\right) \delta 166.0$ (C=O), 160.0 (C-3), 149.5 (C-2), 135.9 (C-8), 135.1 (C-8a), 128.3 (C-5), 128.2 (C-6), 127.1 (C-4), 123.6 (C-4a), $121.9(\mathrm{C}-3), 61.9\left(\mathrm{C}-3^{\prime}\right), 62.0\left(\mathrm{C}-11^{\prime}\right), 55.5\left(\mathrm{C}-2^{\prime}\right), 43.7\left(\mathrm{C}-10^{\prime}\right), 40.8\left(\mathrm{C}-1^{\prime}\right), 40.0$ $\left(\mathrm{C}-5^{\prime}\right), 34.0\left(\mathrm{C}-7^{\prime}\right), 27.7\left(\mathrm{C}-6^{\prime}\right), 26.9\left(\mathrm{C}-4^{\prime}\right), 25.9\left(\mathrm{C}-9^{\prime}\right), 25.5(\mathrm{C}-2 \mathrm{Me}), 20.3\left(\mathrm{C}-8^{\prime}\right) .[\mathrm{M}+\mathrm{H}]^{+}$: $386.1523 \mathrm{~m} / z$ for calculated $\mathrm{C}_{22} \mathrm{H}_{25} \mathrm{ClNO}_{3}$, found $386.1525 \mathrm{~m} / \mathrm{z}$.

\subsection{Plasmodium falciparum Assay}

a. Pf3D7: $100 \mu \mathrm{L}$ of complete media (Sigma-Aldrich's RPMI 1640, 25 mM HEPES, $10 \mu \mathrm{g} / \mathrm{mL}$ gentamicin, $0.5 \mathrm{mM}$ hypoxanthine supplemented with $\mathrm{NaHCO}_{3}$ and $0.5 \%$ Albumax II, $37^{\circ} \mathrm{C}$ ) containing compounds $(50-0.3 \mu \mathrm{M})$ or $100 \mu \mathrm{M}$ chloroquine were added to 96 well plates in triplicates. This was followed by the addition of $100 \mu \mathrm{L}$ erythrocytic asexual culture of Pf3D7 (10\% hematocrit and $0.25 \%$ ring stage parasitemia), maintained at atmospheric conditions of $1 \%$ oxygen, $5 \%$ carbon dioxide, and $94 \%$ nitrogen, and allowed to grow for $96 \mathrm{~h}$ at $37^{\circ} \mathrm{C}$. The cultures were then frozen at $-80^{\circ} \mathrm{C}$ overnight and thawed at $37^{\circ} \mathrm{C}$ for $4 \mathrm{~h}$. Aliquots $(100 \mu \mathrm{L})$ from each well were transferred to black 96 -well plates, $100 \mu \mathrm{L}$ of $2 \times$ SYBR Green (Molecular Probes) in lysis buffer (20 mM Tris at pH 7.5, $5 \mathrm{mM}$ EDTA, $0.008 \%$ saponin, $0.08 \%$ Triton $\mathrm{X}-100$ ) was added to each well and mixed thoroughly with a pipette. The plates were incubated in the dark at room temperature for $1 \mathrm{~h}$ and read at $\lambda_{\mathrm{ex}} 485 \mathrm{~nm}$ and $\lambda_{\mathrm{em}} 530 \mathrm{~nm}$ [27]. Infected and untreated red blood cells (iRBC) cultures served as negative control. Percent inhibitory activities were calculated using $\left(=100-100^{*}((\right.$ Sample $-100 \mu \mathrm{M}$ CQ) /(iRBC - $100 \mu \mathrm{M}$ CQ) $)$ and used to plot sigmoidal inhibition curves to obtain the $\mathrm{EC}_{50}$ values.

b. PfNH54 and PfK1: The growth inhibitory activities of the compounds against erythrocytic stages of $P f \mathrm{NH} 54$ and $P f \mathrm{~K} 1$ were determined using the $\left[{ }^{3} \mathrm{H}\right]$-hypoxanthine incorporation assay as previously reported [28]. Parasites in RPMI 1640 medium containing $5 \%$ Albumax (without hypoxanthine) were treated with compounds $(50-0.3 \mu \mathrm{M})$ in 96 well plates for $48 \mathrm{~h}$ at $37{ }^{\circ} \mathrm{C}$ in $92 \% \mathrm{~N}_{2}, 5 \% \mathrm{CO}_{2}$, and $3 \% \mathrm{O}_{2} \cdot{ }^{3} \mathrm{H}$-hypoxanthine $(0.5 \mu \mathrm{Ci})$ was added to each well, incubated for an additional $24 \mathrm{~h}$, harvested onto glass-fiber filters, and washed with distilled water. Radioactivity at each compound concentration was counted using a Betaplate ${ }^{\mathrm{TM}}$ liquid scintillation counter (Wallac, Zurich), and the results were recorded as counts per minute (CPM) per well. The CPMs were expressed as a percentage of the CPMs from the untreated controls and used to estimate the $\mathrm{EC}_{50}$ from sigmoidal inhibition curves. Artemisinin and CQ were used as positive controls.

\subsection{Cytotoxicity Assay}

Human hepatocarcinoma cell line (Hep G2, ATCC CRL-11997TM) was used for cytotoxicity studies as previously described [29]. The cells were grown in complete medium (DMEM:F12 containing L-glutamine and sodium bicarbonate, $10 \%$ FBS, $1 \%$ penicillin/streptomycin, Thermo Fisher Scientific) at $37{ }^{\circ} \mathrm{C}$ in $5 \% \mathrm{CO}_{2}$ environment. Cells $(198 \mu \mathrm{L}, 5 \times 105 / \mathrm{mL})$ were seeded into 96 -well plates and incubated overnight. The cells were treated with the compounds (160-1.25 $\mu \mathrm{M}$, in triplicates) or DMSO (1\%) for $72 \mathrm{~h}$. The cell medium was removed and replaced with DMEM:F12 medium containing MTT $(0.5 \mathrm{mg} / \mathrm{mL})$ was added to the cells and incubated for $1.5 \mathrm{~h}$. The MTT-containing medium was gently removed and replaced with DMSO $(200 \mu \mathrm{L} /$ well $)$. The contents of each well were then repeatedly mixed with a multichannel pipette and incubated for $10 \mathrm{~min}$. The plates were read at $570 \mathrm{~nm}$. DMSO-treated (1\%) cells were used as negative assay control and SDS (10\%) was used as assay positive control. Percent cell viabilities were expressed as a percentage of the mean viability of DMSO-treated (1\%) cells.

Supplementary Materials: The following are available online. ${ }^{1} \mathrm{H},{ }^{13} \mathrm{C}$, and HRMS Data (Figure S1.1a-S1.16b). 
Author Contributions: Conceptualization, R.J.N. and I.V.O.; methodology, R.J.N., H.Z., J.T.C., O.C, I.V.O.; formal analysis, R.J.N., H.Z., J.T.C., O.C., I.V.O.; resources, I.V.O.; investigation, R.J.N., H.Z., J.T.C., O.C., I.V.O.; data curation, R.J.N., H.Z., J.T.C., O.C., I.V.O.; writing-original draft preparation, R.J.N. and I.V.O.; writing-review and editing, R.J.N. and I.V.O.; supervision, I.V.O.; project administration, I.V.O.; funding acquisition, I.V.O. All authors have read and agreed to the published version of the manuscript."

Funding: This research was partly funded by the US National Institutes of Health, SC3GM122629 and G12MD007581. J.T.C. was supported by The National Science Foundation (NSF) HBCU-RISE Program (HRD-1547836). O.C. was supported in part by the American Association of University Women (AAUW).

Institutional Review Board Statement: Not applicable.

Informed Consent Statement: Not applicable.

Data Availability Statement: Data is contained within the article or supplementary material.

Acknowledgments: We thank Marcel Kaiser (Swiss Tropical and Public Health Institute, Basel, Switzerland) for technical assistance with the Plasmodium assays.

Conflicts of Interest: The authors declare no conflict of interests.

Sample Availability: Samples of the compounds 1-16 are available from the authors.

\section{References}

1. Centers for Disease Control and Prevention (CDC). Malaria. Available online: https://www.cdc.gov/parasites/malaria/index. html (accessed on 12 January 2020).

2. World Health Organization (WHO). Global Malaria Programme. Available online: https://www.who.int/teams/global-malariaprogramme (accessed on 12 January 2020).

3. Witkowski, A.B.; Amaratunga, C.; Beghain, J.; Langlois, A.C.; Khim, N.; Kim, S.; Duru, V.; Bouchier, C.; Ma, L.; Lim, P.; et al. A Molecular Marker of Artemisinin-resistant Plasmodium falciparum malaria. Nature 2014, 505, 50-55. [CrossRef]

4. Slater, A.F.; Swiggard, W.J.; Orton, B.R.; Flitter, W.D.; Goldberg, D.E.; Cerami, A.; Henderson, G.B. An iron-carboxylate bond links the heme units of malaria pigment. Proc. Natl. Acad. Sci. USA 1991, 88, 325-329. [CrossRef]

5. Sullivan, D.J.; Matile, H.; Ridley, R.; Goldberg, D.E. A Common Mechanism for Blockade of Heme Polymerization by Antimalarial Quinolines. J. Biol. Chem. 1998, 47, 31103-31107. [CrossRef]

6. Sullivan, D.J., Jr.; Gluzman, I.Y.; Goldberg, D.E. Plasmodium hemozoin formation mediated by histidine-rich proteins. Science 1996, 271, 219-222. [CrossRef] [PubMed]

7. Martiney, J.A.; Cerami, A.; Slater, A.F. Inhibition of Hemozoin formation in Plasmodium falciparum trophozoite extracts by heme analogs: Possible Implication in the Resistance to Malaria conferred by the $\beta$-thalassemia trait. Mol. Med. 1996, 2, $236-246$. [CrossRef] [PubMed]

8. Egan, T.J.; Combrinck, J.M.; Egan, J.; Hearne, G.R.; Marques, H.M.; Ntenteni, S.; Sewell, B.T.; Smith, P.J.; Taylor, D.; Van Schalkwyk, D.A.; et al. Fate of Haem Iron in the malaria parasite Plasmodium falciparum. Biochem. J. 2002, 365, 343-347. [CrossRef] [PubMed]

9. Wicht, K.J.; Mok, S.; Fidock, D.A. Molecular mechanisms of drug resistance in Plasmodium falciparum malaria. Annu. Rev. Microbiol. 2020, 74, 431-454. [CrossRef] [PubMed]

10. Rawe, S.L.; McDonnell, C. The cinchona alkaloids and the aminoquinolines. In Antimalarial Agents; Patrick, G.L., Ed.; Elsevier: Amsterdam, The Netherlands, 2020; pp. 65-98.

11. Kim, J.; Tan, Y.Z.; Wicht, K.J.; Erramilli, S.K.; Dhingra, S.K.; Okombo, J.; Vendome, J.P.; Hagenah, L.M.; Giacometti, S.I.; Potter, C.S.; et al. Structure and Drug Resistance of the Plasmodium falciparum Transporter PfCRT. Biophys. J. 2020, 118, 523a. [CrossRef]

12. Sá, J.M.; Kaslow, S.R.; Barros, R.R.M.; Brazeau, N.F.; Parobek, C.M.; Tao, D.; Salzman, R.E.; Gibson, T.J.; Velmurugan, S.; Krause, M.A.; et al. Plasmodium vivax chloroquine resistance links to pvcrt transcription in a genetic cross. Nat. Commun. 2019, 10, 4300. [CrossRef]

13. Camarda, G.; Jirawatcharadech, P.; Priestley, R.S.; Saif, A.; March, S.; Wong, M.H.; Leung, S.; Miller, A.B.; Baker, D.A.; Alano, P.; et al. Antimalarial activity of primaquine operates via a two-step biochemical relay. Nat. Commun. 2019, 10, 3226. [CrossRef] [PubMed]

14. Fasinu, P.S.; Nanayakkara, N.D.; Wang, Y.H.; Chaurasiya, N.D.; Herath, H.B.; McChesney, J.D.; Avula, B.; Khan, I.; Tekwani, B.L.; Walker, L.A. Formation primaquine-5,6-orthoquinone, the putative active and toxic metabolite of primaquine via direct oxidation in human erythrocytes. Malar. J. 2019, 18, 30. [CrossRef]

15. Van Zyl, R.L.; Seatlholo, S.T.; van Vuuren, S.F. The biological activities of 20 nature identical essential oil constituents. J. Essent. Oil Res. 2006, 18, 129-133. [CrossRef] 
16. Bharate, S.B.; Singh, I.P. A two-step biomimetic synthesis of antimalarial robustadials A and B. Tetrahedron Lett. 2006, 47, 7021-7024. [CrossRef]

17. Il'ina, L.; Volcho, K.; Korchagina, D.; Salakhutdinov, N.; Barkhash, V. Transformations of Epoxide Derived from Nopol over Askanite-Bentonite Clay. Russ. J. Org. Chem. 2019, 40, 1432-1436. [CrossRef]

18. Cabrera, M.; Cui, L. In vitro activities of primaquine-schizonticide combinations on asexual blood stages and gametocytes of Plasmodium falciparum. Antimicrob. Agents Chemother. 2015, 59, 7650-7656. [CrossRef] [PubMed]

19. Boudhar, A.; Ng, X.W.; Loh, C.Y.; Chia, W.N.; Tan, Z.M.; Nosten, F.; Dymock, B.W.; Tan, K.S.W. Overcoming chloroquine resistance in malaria: Design, synthesis, and structure-activity relationships of novel hybrid compounds. Antimicrob. Agents Chemother. 2016, 60, 3076-3089. [CrossRef]

20. Richards, S.N.; Nash, M.N.; Baker, E.S.; Webster, M.W.; Lehane, A.M.; Sharik, S.H.; Martin, R.E. Molecular Mechanisms for Drug Hypersensitivity Induced by the Malaria Parasite's Chloroquine Resistance Transporter. PLoS Pathog. 2016, 12, e1005725. [CrossRef]

21. Reddy, M.D.; Kobori, H.; Mori, T.; Wu, J.; Kawagishi, H.; Watkins, E.B. Gram-scale, stereoselective synthesis and biological evaluation of (+)-armillariol C. J. Nat. Prod. 2017, 80, 2561-2565. [CrossRef]

22. Yang, D.; Jiao, G.S.; Yip, Y.C.; Wong, M.K. Diastereoselective epoxidation of cyclohexene derivatives by dioxiranes generated in situ. Importance of steric and field effects. J. Org. Chem. 1999, 64, 1635-1639. [CrossRef] [PubMed]

23. Hashimoto, N.; Kanda, A. Practical and environmentally friendly epoxidation of olefins using oxone. Org. Process Res. Dev. 2002, 6, 405-406. [CrossRef]

24. Caprino, L. 1-Hydroxy-7-azabenzotriazole. An efficient peptide coupling additive. J. Am. Chem. Soc. 1993, 115, 4397-4398. [CrossRef]

25. Park, Y.; Fei, X.; Yuan, Y.; Lee, S.; Joonseong, H.; Jean, S.; Jung, J.; Seo, S. Chemoselective acylation of 2-amino-8-quinolinol in the generation of C2-amides or C8-esters. RSC Adv. 2017, 7, 41955-41961. [CrossRef]

26. Denmark, S.; Forbes, D.C.; Hays, D.S.; DePue, J.S.; Wilde, R.G. Catalytic Epoxidation of Alkenes with Oxone. J. Org. Chem. 1997, 62, 1397-1407. [CrossRef] [PubMed]

27. Smilkstein, M.; Sriwilaijaroen, N.; Kelly, J.X.; Wilairat, P.; Riscoe, M. Simple and inexpensive fluorescence-based technique for high-throughput antimalarial drug screening. Antimicrob. Agents Chemother. 2004, 48, 1803-1806. [CrossRef] [PubMed]

28. Matile, H.; Pink, J.R.L. Plasmodium falciparum malaria parasite cultures and their use in immunology. In Immunological Methods; Lefkovits, I., Pernis, B., Eds.; Academic Press: San Diego, CA, USA, 1990; pp. 221-234.

29. Zhang, H.; Collins, J.; Nyamwihura, R.; Ware, S.; Kaiser, M.; Ogungbe, I. Discovery of a quinoline-based phenyl sulfone derivative as an antitrypanosomal agent. Bioorg. Med. Chem. Lett. 2018, 28, 1647-1651. [CrossRef] [PubMed] 